\title{
LA INDUSTRIALIZACIÓN DEL BOSQUE \\ EN LA ESPAÑA INTERIOR: PRODUCCIÓN \\ Y CAMBIO TÉCNICO EN LA INDUSTRIA \\ RESINERA (1860-1914) ${ }^{1}$
}

R. URIARTE AYO

Universidad del País Vasco

\section{RESUMEN}

Este artículo estudia el proceso de modernización de la industria resinera española, una de las actividades de mayor implantación en las extensas masas de coníferas existentes, sobre todo, en la meseta norte castellana. A partir de una tradición campesina previa, el sector fue penetrado por nuevas técnicas y empresarios, transformándose, a fines del siglo XIX, en una de las ramas más relevantes de la química española, con una notable presencia en los mercados internacionales.

\section{ABSTRACT}

This paper studies the process of modernization of the Spanish resin industry, one of the most widespread activities in the vast coniferous woodlands existing, above all, in the northern Castilian meseta. Starting from a previous peasant tradition, the sector was transformed by new techniques and entrepreneurs at the end of the 19th century, into one of the most relevant branches of the Spanish chemical industry, with an important presence in international markets.

1 La realización del presente estudio ha sido posible gracias a la financiación por parte de la Universidad del País Vasco de un proyecto de investigación (012.321-HA209/93) sobre La modernización de la industria rural: los sectores agroalimentario y forestal. Quisiera agradecer la amabilidad de José Luis Bordons, quien me ha facilitado el acceso a los archivos de L.U.R.E. Asimismo debo de expresar mi gratitud hacia Santiago Zapata y José Ignacio Jiménez Blanco por las observaciones y sugerencias realizadas al texto original. 


\section{INTRODUCCIÓN}

Uno de los hechos más destacados en la reciente historiografía acerca de la industrialización en España es la atención prestada a los llamados sectores «no líderes». Tal como ha señalado el profesor Nadal, no es posible continuar estudiando la industria de los siglos XIX y XX en términos de algodón y siderurgia. Si se quiere romper una visión parcial y deformada de la realidad, es necesario abandonar viejos esquemas e integrar de forma ponderada los diferentes sectores que componen la moderna estructura industrial de la economía española ${ }^{2}$. Por otro lado, el interés por nuevas industrias, ramas o sectores productivos, ha modificado el marco territorial de nuestro análisis. Sabíamos que la industrialización es un fenómeno de alcance regional y, de hecho, buena parte de la historiografía «tradicional» ha tenido siempre la región o la provincia como ámbito de referencia básico. Sin embargo, la necesidad de abordar nuevos sectores productivos ha reforzado el interés por determinados desarrollos regionales que habían permanecido «ocultos» o mal representados 3 .

La importancia del bosque y sus diversos aprovechamientos ha sido reiterada en diversas ocasiones, siendo el Grupo de Estudios de Historia Rural quien más ha contribuido a su estudio ${ }^{4}$. Sin embargo, las industrias forestales no han merecido todavía una atención suficiente y siguen siendo uno de los huecos significativos que es necesario cubrir. En España, dado el atraso y la relativa debilidad de la industria durante el siglo XIX y primera mitad del XX, buena parte de los usos primitivos del bosque se han mantenido vigentes hasta tiempos muy recientes. Sin embargo, las transformaciones operadas a lo largo del citado período fueron sin duda considerables y los bosques han logrado conservar su estratégica importancia en nuevos usos y áreas de actividad. Tras los cambios jurídicos introducidos por las leyes desamortizadoras y las específicas referidas a la gestión de los montes públicos, a partir del último cuarto del siglo XIX y durante las primeras décadas del XX, los montes españoles, tanto públicos como privados, fueron siendo incorporados a nuevas formas de aprovechamiento y explotación, permitiendo el desarrollo de una industria de la madera, el corcho, la resina o el papel de dimensiones significativas, incluso desde la perspectiva internacional.

2 J. Nadal (1987), pp. 23-24. La redistribución de nuestros programas de Historia Económica en beneficio de las etapas más recientes y la necesidad de ofrecer una explicación coherente del panorama industrial que en la actualidad conocemos, ha contribuido a hacer más patente si cabe la necesidad de disponer de una visión mucho más rica de nuestro pasado industrial.

3 J. Nadal, A. Carreras (1990).

+ Aunque en la bibliografía final se recogen las referencias con mayor amplitud, algunas de las contribuciones más recientes y significativas serian: J. Sanz Fernández (1985) y (1986), S. Zapata Blanco (1986), C. Ortega Hernández-Agero (coord.) (1989), J. I. Jiménez Blanco (1991), G.E.H.R. (1991) y (1994), J. Gómez Mendoza (1992). 
La resina natural, miera o trementina, de cuya industria nos ocuparemos en las páginas que siguen, es un producto extraído mediante incisiones practicadas en el tronco de diferentes especies forestales, principalmente coníferas y algunas terebintáceas. Tras su procesamiento, mediante destilación, se fracciona, dando lugar a la esencia de trementina o aguarrás y a la colofonia o resina del comercio, productos posteriormente empleados en diferentes procesos industriales (fabricación de barnices, pinturas, disolventes, insecticidas, jabón, aceites industriales, papel, aislantes eléctricos, cerillas, etc.). España, con una climatología apropiada e importantes recursos forestales, pudo desarrollar una importante industria resinera, fuertemente orientada a la exportación y representativa del dinamismo de un subsector donde se operaron transformaciones decisivas en fechas relativamente tempranas.

\section{TÉCNICAS Y PROCEDIMIENTOS INDUSTRIALES}

\subsection{El empleo industrial de la resina}

Desde la antigüedad, la resina procedente de las coníferas fue empleada principalmente en forma de alquitrán, brea y pez, siendo sus principales consumos el calafateado de los barcos, la impregnación de las cuerdas de cáñamo, la conservación de la madera, la iluminación y otras numerosas aplicaciones vinculadas casi siempre a la industria naval, de ahí la denominación inglesa de naval stores que todavía en la actualidad reciben genéricamente los productos resinosos ${ }^{5}$. Los países escandinavos, Rusia, Polonia y, en menor medida, la región francesa de Las Landas, han sido los grandes productores de la Europa preindustrial y abastecedores de los principales mercados occidentales. A partir del siglo XVII, a medida que avanzó la colonización inglesa en Norteamérica, los bosques del nuevo continente empezaron a ser sistemáticamente explotados con este fin y proporcionaron a Inglaterra una de las materias básicas para el desarrollo de su flota. Desde mediados del siglo XVIII, en un proceso muy vinculado al avance de la industrialización y, particularmente, a los progresos alcanzados en la primera industria química, las aplicaciones de la resina fueron cambiando y el consumo se diversificó y transformó. Aunque las necesidades de la marina seguían siendo decisivas, crecía el consumo de colofonias y esencia de trementina, primeros derivados obtenidos por destilación de la resina. Por otro lado, ya en el siglo XIX, a medida que el hierro sustituyó a la madera en la cons-

A. W. Schorger, 1915, p. 2. Para una visión general del sector a lo largo de la historia, pueden verse T. Gamble (1921) y J. Drew (1989). 
trucción naval y el alquitrán empezó a ser obtenido con un coste menor mediante la destilación de la hulla, los productos más tradicionales fueron perdiendo importancia y la obtención de la resina se vinculó definitivamente a la producción de colofonias y esencia de trementina ${ }^{6}$.

Sería realmente difícil enumerar los numerosos y siempre cambiantes empleos industriales donde intervenían la colofonia y la esencia de trementina. De hecho, hasta fechas muy tardías, no disponemos de estadísticas de consumo que nos permitan observar los cambios en la composición y estructura del mercado. Sabemos, no obstante, que hasta muy entrado el siglo $\mathrm{XX}$ dominaron lo que podrían calificarse como empleos industriales directos ${ }^{7}$. En lo que se refiere a la trementina, las principales aplicaciones se debían a sus propiedades como disolvente de materias grasas y durante mucho tiempo la fabricación de pinturas y barnices constituyó su principal uso industrial. Igual propiedad fue la que en la segunda mitad del siglo XVIII introdujo el empleo de la esencia de trementina como disolvente del caucho ${ }^{8}$ y en la limpieza de maquinaria, sobre todo en los barcos a vapor y en ferrocarriles ${ }^{9}$. Además de las citadas aplicaciones, la esencia de trementina se empleaba en el curtido de pieles, fabricación de insecticidas, veterinaria y farmacia, y, mezclada con alcohol, para el alumbrado doméstico. Para la colofonia, los usos más extendidos serían, la fabricación de jabón, cola de papel, aceites y grasas industriales, lacres, betún, negro de.humo, productos esteáricos, alquitranes, revestimiento de los barriles de cerveza, etc. De entre ellos, al menos por lo que se refiere a la industria española, la fabricación de jabón fue el sector que mayor volumen de colofonias absorbía. Se trataba de jabones blandos, fácilmente solubles en agua, por lo que su consumo tenía lugar sobre todo en las regiones periféricas, particularmente del Mediterráneo ${ }^{10}$. Por otro lado, este tipo de jabones eran los requeridos en la industria textil para el batanado y desengrasado de la lana, lo cual les otorgaba su verdadero carácter industrial, siendo Cataluña su principal región de consumo ${ }^{11}$. Aunque los datos son relativamente tardíos, hacia

- G. Dupont (1926), p. 158. En los países escandinavos, no obstante, durante el siglo XIX se mantuvo una importante industria orientada todavía a la producción de alquitrán y brea con destino al sector naval. Fue el incremento del precio de la madera asociado a la demanda procedente de la industria papelera lo que a fines del siglo XIX acabaría por eliminar dicha actividad (J. Drew, 1989, p. 10).

${ }^{7}$ Un análisis reciente de la evolución de los diferentes consumos de resina puede verse en $D$. F. Stauffer (1989), pp. 39-80.

${ }^{8}$ Según patente de Samuel Peal fechada en 1791 (S. S, Pickles, 1980, p. 756).

${ }^{9}$ R. Xérica (1869), p. 103.

10 A excepción de Castilla, donde la calidad de las aguas permitía diluir más fácilmente el jabón, por lo que se prefería la utilización de las clases más duras, en las regiones periféricas y, muy especialmente en el área mediterránea, resultaban mäs adecuados los jabones blandos resinosos (Anónimo 1930, p. 15).

"J. Poch Noguer (1918), p. 97, y Memoria L. U.R.E. 1898, p. 23. 
1930, en España se estimaba que el 85 por 100 del consumo interno de colofonia (unos $12.750 .000 \mathrm{~kg}$ ) era absorbido por la fabricación de jabones de aceite de semillas, principalmente de coco. En la producción del papel, el otro gran consumidor de colofonias ${ }^{12}$, su introducción se produjo a partir de la industria alemana a principios del siglo $\mathrm{XIX}^{13} \mathrm{y}$ ha sido el único sector de los tradicionales donde su consumo se ha mantenido hasta la actualidad en todos los países. Las grasas consistentes elaboradas a base de colofonia eran principalmente empleadas como lubricantes en los carruajes, ferrocarriles, engranajes de maquinaria, etc., siendo su principal cualidad el mantener constante su consistencia, lo cual permitía su empleo en cualquier estación del año ${ }^{14}$.

\subsection{Técnicas de extracción}

Las sucesivas transformaciones en el empleo de la resina han ido acompañadas de cambios en los procedimientos utilizados para su extracción y tratamiento. Aunque la esencia de trementina era conocida y utilizada desde la Antigüedad, hasta el siglo XIX el principal interés se centraba en la obtención del alquitrán. Para ello se seguían métodos adaptados a las condiciones climáticas y las características del arbolado existentes en cada zona. En los países del norte de Europa, las bajas temperaturas existentes durante gran parte del año impedían que la resina pudiera ser obtenida por secreción ${ }^{15}$. En estas áreas el procedimiento consistía en carbonizar lentamente la madera en rudimentarios hornos, donde el alquitrán destilado se recogía en forma líquida en un recipiente o simple foso situado en la base de la estructura ${ }^{16}$. Sistemas semejantes fueron empleados en otras áreas de Europa hasta bien entrado el siglo XIX. Sin embargo, en la Europa meridional, allí donde

12 R. Xérica (1869), p. 107, estimaba que la colofonia representaba el dos por ciento del peso final del papel.

${ }_{13}$ Concretamente, fue en 1806 cuando los fabricantes alemanes empezaron a sustituir las tradicionales colas elaboradas a base de grasa animal por la colofonia, consiguiendo abaratar los costes finales $(\mathrm{J}$. A. McGaw, 1987, pp. 206-2111.

${ }_{14}$ Además, dado su bajo precio, este tipo de grasas había sustituido a los lubricantes elaborados a base de grasas animales o con jabones de ácidos grasos (J. Iturralde, O. Elorrieta, 1914, p. 133, y M. Tomeo, 1939, p. 325).

15 «La resinación del pino silvestre en un clima tan frio (especialmente por la noche) como el de las regiones donde se verifica dicho aprovechamiento no permite la recolección de la miera en forma análoga a como se realiza en España, Francia, etcétera, cuando se resinan los pinos sometidos a dicho aprovechamiento. A causa del frío indicado, la trementina se solidifica a su salida de los canales resiníferos, y perdiendo fluidez, no puede deslizarse a lo largo de la cara, depositándose, como consecuencia, sobre esta última» (L. Vélaz de Medrano, 1924, p. 532).

16 J. Drew (1989), p. 10. 
existieran masas forestales adecuadas, las condiciones climáticas permitían que la resina se obtuviera estimulando la secreción natural de los árboles por medio de entalladuras realizadas en su tronco. De este modo, junto a la producción clásica de alquitrán, según el método descrito, pudo desarrollarse una industria diferenciada en base al tratamiento directo de la resina. En estos casos, el producto primario obtenido es la trementina, conocida como miera en España, siendo la esencia de trementina y la colofonia sus primeros derivados.

Tradicionalmente, la práctica de la resinación se ha efectuado de acuerdo con dos procedimientos: a vida y a muerte. En la resinación a muerte, a pila, o pino perdido el objetivo prioritario era extraer la mayor cantidad de miera en el menor espacio de tiempo posible. El procedimiento consistía en abrir simultáneamente todas las entalladuras posibles (caras) en el contorno del tronco, con lo cual, sacrificando la vida del árbol, en unos pocos años se agotaba su producción y el árbol moría. Por lo general, a partir de la segunda mitad del siglo XIX la resinación a muerte va siendo progresivamente abandonada y tan sólo se sigue practicando cuando se realizaban cortas de mejora o en árboles plenamente maderables ${ }^{17}$. En la resinación a vida, en lugar de abrir simultáneamente todas las caras, las incisiones se practicaban de forma ordenada en una sola entalladura, de acuerdo con unas dimensiones previamente establecidas e intercalando siempre períodos de reposo, de manera que el desarrollo del árbol se ve menos afectado y su aprovechamiento puede prolongarse por un espacio superior, en ocasiones, a los cincuenta años. Con ello, al tiempo que se ampliaba el aprovechamiento de la masa forestal y se reducía su deterioro, se hacía compatible la extracción regular de la resina, con el crecimiento del arbolado y la producción útil de madera ${ }^{18}$.

En el primitivo procedimiento de resinación a muerte, tras haber realizado en el tronco incisiones lo más anchas y profundas posible, el jugo resinoso se canalizaba hacia la base del árbol, lugar donde previamente se había preparado una simple cavi-

${ }_{17}$ «Quand le pin est mur et bon pour la vente, on le résine à mort ou à ruine pendant une période de quatre années. On dispose alors quatre pots au bas de quatre cares parallèles. C'est ainsi que l'on avait procédé, pour recueillir la résine, avec les jeunes arbres d'eclaircissage destinés à être vendus comme poteaux de mine. Mais, sur ces vieux pins destinés à faire des madriers et des planches, pour épuiser plus complètement la gemme, ce nombre habituel de quatre cares augmente avec la grosseur; c'est parfois un chapelet de huit ou dix pots qui s'enguirlande autour de ces troncs énormes» (X. Cardillac, 1908, pp. 10-11).

${ }_{18}$ En realidad, los diferentes sistemas de resinación a vida conocidos seguían dañando, en mayor o menor medida, el desarrollo vegetativo del árbol: «sabido es que la extracción de resinas, aunque por ello no desmerece la calidad de la madera, disminuye si su crecimiento y al tratarse de aprovechamientos maderables, siempre queda inutilizada o de escaso valor la troza más inferior o sea la que al resinar ha sido herida; recomendándose siempre por esta causa para ser resinados, aquellos montes en que abunden los pinos mal conformados, torcidos, defectuosos o de escasas dimensiones de altura» (A.M.A., Montes, 70/6, Segovia, 1888). 
dad (boya) que actuaría de recipiente para la recogida de la miera ${ }^{19}$. En la resinación a vida, los diferentes sistemas y variantes se distinguían por el modo en que se trabajaban las caras y los dispositivos empleados para recoger la miera. En los principales países productores de Europa (Francia, España y Portugal), con pequeñas variantes, las entalladuras se hacían de forma tangencial y alargada, siguiendo el eje del árbol. En su dimensión máxima la cara podía alcanzar una altura de unos 4 metros y un ancho de unos 12 centímetros, adquiriendo forma de $\mathbf{U}$ invertida. Por el contrario, de acuerdo con el sistema seguido en América, la cara estaba formada por dos lados, en forma de $\mathbf{V}$ muy abierta, era sensiblemente más ancha que la cara europea (hasta 35 centímetros), aunque la altura resultaba considerablemente menor ${ }^{20}$. En cuanto a los procedimientos utilizados para la recogida de la miera, el más primitivo era el practicado inicialmente en la resinación a muerte, que consistía, como se ha visto, en abrir una cavidad en la base del árbol, junto a la correspondiente entalladura. Se trataba del procédé au crot francés que, aunque de forma cada vez más marginal, se siguió practicando en algunos países de Europa (Grecia y Portugal) hasta principios del siglo $\mathrm{XX}^{21}$. El citado sistema, además de dañar la calidad del producto, debido a la inevitable acumulación de materiales extraños (hojas, tierra, insectos, etc.), provocaba importantes pérdidas de rendimiento debido a la evaporación y oxidación de la trementina en su largo recorrido hasta la boya. La primera variación introducida fue el box-system americano, en el cual la cavidad se trasladaba al mismo tronco del árbol, tallándola en la base de la cara. De este modo se conseguía sobre todo disminuir la incorporación de impurezas, pero seguían produciendose pérdidas por evaporación y oxidación. Además, se añadían nuevos problemas, dado que los árboles tratados de este modo se veían enormemente debilitados, eran derribados con facilidad por el viento y tenían un menor aprovechamiento maderero ${ }^{22}$. En Europa, a partir de mediados del siglo XIX comenzó a extenderse con éxito el sistema Hugues ${ }^{23}$. En este caso la recogida de la miera se

19 «Se abren con hacha, los recipientes para recoger la Miera en alguna raíz gruesa o en trozos de ramas que se colocan al pie del árbol; pero lo más común, es hacer unos pequeños agujeros en el suelo, al lado mismo del cuello de la raíz, reforzando las paredes con tierra o con musgo» (R. Xérica, 1869, p. 54).

${ }^{20} \mathrm{M}$. Tomeo (1939), p. 45. Al margen de las diferentes prácticas existentes en cada zona, al menos en lo que respecta a los montes públicos, las labores de resinación estaban muy reglamentadas y era necesario respetar las condiciones impuestas por la normativa general vigente en cada caso y la específica establecida en las correspondientes subastas.

${ }^{21}$ M. Tomeo (1939), pp. 45.46.

22 M. Tomeo (1939), p. 46.

23 Hacia 1840 Hugues, empresario del sector en la localidad de Tarnos, cercana a Bayona, trató de introducir su procedimiento sin éxito, muriendo prácticamente arruinado en 1850 (E. Rabaté, 1902, p. 46). Posteriormente, el sencillo método ideado por Hugues se generalizó en Las Landas francesas a partir de 1857 (A. Larroquette, 1935, p. 232) y, como se indica más adelante, fue aplicado por primera vez en España a partir de 1862 en los pinares de Coca (Segovia) explotados por La Resinera Segoviana. 
hacía mediante un recipiente móvil de barro (pote), de forma tronco-cónica, vidriado en su interior y ligeramente aplastado en el exterior para su mejor adaptación al tronco. En cada campaña, el recipiente era clavado en el lugar preciso de la nueva incisión y se empleaba una pequeña lámina rectangular de zinc (grapa o crampón) fijada al tronco para guiar y facilitar la salida de la trementina. Frente a los métodos utilizados hasta entonces, el empleo de vasijas móviles permitía reducir la distancia recorrida por la trementina hasta llegar al recipiente, con lo cual se evitaban pérdidas por evaporación, se aumentaba y regularizaba la producción a lo largo de los cinco años de explotación de la cara, y la trementina se recogía con mayor limpieza y con una coloración más estable. De hecho, en España, al igual que en Francia, la introducción del sistema Hugues marcó una neta diferenciación de precios, pagándose las resinas obtenidas por el citado procedimiento hasta un veinte por ciento más caras ${ }^{24}$.

A pesar de que existieron importantes resistencias sociales, las evidentes ventajas del nuevo método, su sencillez y bajo costo, facilitaron su rápida difusión en Francia y, posteriormente, en España a partir de los años sesenta, coincidiendo con la excepcional coyuntura asociada a la Guerra de Secesión americana. En los Estados Unidos, en cambio, el box-system se siguió utilizando hasta final del siglo XIX, provocando la destrucción de enormes extensiones de arbolado en los estados del sureste del país. A partir de 1900 se implantó en América el cup and gutter system, muy semejante al Hugues practicado en Europa, aunque adaptado al perfil de la entalladura característica americana ${ }^{25}$.

Por imperativos climatológicos, la resinación ha sido siempre un trabajo de carácter estacional. Teóricamente, la trementina fluye de los pinos de una manera continua. Sin embargo, la secreción es más abundante en los meses centrales del verano y disminuye, hasta prácticamente desaparecer, en el invierno. En España, de manera general, los trabajos se iniciaban a mediados del mes de febrero y concluían en noviembre. No obstante, dependiendo de las variaciones climáticas de cada zona, la campaña podía tener pequeñas variaciones de calendario.

De acuerdo con la descripción del sector recogida en la obra de R. Xerica ${ }^{26}$, los operarios empleados en la resinación (pegueros), iniciaban su labor eliminando la corteza del árbol (sin dejar descubierta la albura) hasta formar una superficie regular y lisa de dimensiones algo superiores a la cara que debía formarse durante la campaña, para lo cual hacian uso de un hacha común, algo más pesada que las ordinarias, denominada barrasco. El descortezamiento o desroñe se iniciaba en el mes de febrero y debía concluir a principios de marzo. La finalidad perseguida era facilitar las posteriores

\footnotetext{
${ }^{24}$ R. Xérica (1869), p. 56.

${ }^{25}$ M. Tomeo (1939), p. 48.

26 R. Xérica (1869).
} 
incisiones, aumentar la acción del sol sobre la albura, favoreciendo la secreción de los jugos resinosos, y ayudar a su recogida ${ }^{27}$. Una vez retirada la corteza, se realizaban las entalladuras, incisiones rectangulares practicadas anualmente hasta formar una cara. Dicha operación se llevaba a cabo mediante la escoda, herramienta semejante a una azuela con la superficie de corte de forma cóncava. Tras varios días en los que la miera fluía libremente, la incisión acababa por obstruirse y se debía realizar una nueva pica unos centímetros por encima del anterior corte. Aunque la frecuencia podía variar en función del clima de cada zona, generalmente las picas se practicaban dos veces por semana y, en todo caso, tenían que ser más frecuentes durante la primavera y el otoño que en el verano. Para la recogida de la resina, operación denominada remasada y que en los meses centrales del verano se hacía cada quince días, los operarios vertían el contenido de los potes en unas latas o garrafones y después lo introducían en barricas de madera proporcionadas por la misma empresa. Seguidamente, la miera era conducida a la fábrica y recibida por un operario encargado de efectuar un primer control de calidad, estimando la cantidad de agua e impurezas sólidas contenida en cada barrica, para descontarla del peso total de la miera entregada por cada resinero.

Transcurridos cuatro o cinco años de aprovechamiento, la cara alcanzaba una altura media de cuatro metros. De este modo, las entalladuras realizadas durante los dos primeros años podían ejecutarse «a pie firme», mientras que para las siguientes era necesario utilizar toscas escaleras o una especie de azadilla de mango largo, lo cual hacía más lento y penoso el trabajo ${ }^{28}$. Por otro lado, el rendimiento también variaba conforme se realizaban nuevas entalladuras; siendo las primeras las que proporcionaban una mayor cantidad de resina, era necesario incrementar progresivamente sus dimensiones para garantizar un rendimiento constante, aspectos que, tanto en España como en los restantes países productores, estuvieron regulados por ley en lo que se refiere a los montes de propiedad pública ${ }^{29}$. Por lo general,

${ }^{27}$ R. Xerica (1869), p. 49.

${ }_{28}$ En los dos primeros años R. Xerica estima que un resinero podía llegar a abrir de forma cómoda de 1.200 a 1.300 entalladuras al dia. Sin embargo, a partir del tercero el rendimiento sería menor pues «tiene que valerse de la escalera, y por consiguiente su trabajo es más difícil y penoso, sufriendo fatigas que no podrían soportar los obreros que no estuviesen a él acostumbrados: así se les ve con la hacha en una mano y la escalera en la otra, correr de árbol en árbol, entre arbustos y malezas, subir por la escalera con una pasmosa agilidad, refrescar la herida del Pino, saltar al suelo, y repetir sin cesar la misma operación» (R. Xerica, 1869, p. 50).

${ }^{29}$ La Real Orden de 23 de abril de 1863 estableció las siguientes dimensiones para aquellos aprovechamientos que requerían la aprobación del Ministerio de Fomento:

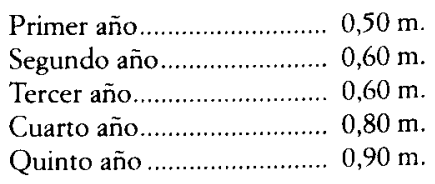


en la resinación a vida tan sólo se labraba una cara y, tras los cuatro o cinco años, se abría una nueva, hasta completar, de forma sucesiva, cuatro caras distribuidas en el contorno del árbol. Concluido un primer ciclo, el proceso podía repetirse abriendo nuevas caras en los espacios intermedios, de manera que la explotación se prolongaba por espacio de cincuenta o sesenta años. Si el árbol había empezado a ser resinado a los veinticinco años de edad, cuando contaba con setenta y cinco u ochenta era resinado a muerte o pino perdido, de acuerdo con el sistema descrito anteriormente ${ }^{30}$.

\subsection{Tratamiento y primera transformación}

De acuerdo con lo que sabemos del desarrollo primitivo de esta actividad, hasta principios del siglo XIX, la miera extraída según el sistema de resinación $a$ muerte, era simplemente sometida a cocción en una caldera de cobre calentada en un horno de ladrillo y arcilla. El producţo, una vez limpio de impurezas, era vertido en una gran pila de madera, añadiéndose posteriormente una cierta cantidad de agua hirviendo y, tras batir la mezcla durante unos minutos, se dejaba reposar y enfriar, para finalmente solidificarlo en forma de pequeños panes de resina. Se trataba de la llamada resina amarilla, resina opaca o pez-resina, cuya aplicación más extendida en un principio fue la fabricación de velas y, posteriormente, la elaboración de jabones empleados en la industria papelera. Los residuos de todo tipo impregnados en materia resinosa (hojas, virutas, tierra, etc.) eran sometidos igualmente a cocción en hornos de montaña denominados pegueras en España, obteniéndose una pez negra utilizada también para el calafateado de los barcos y con fines medicinales ${ }^{31}$.

La primera innovación significativa fue el paso de la simple cocción de la miera a que ésta fuera destilada por medio de alambiques. De acuerdo con R. Sargos, la destilación industrial de la resina empezó a practicarse en Francia a partir de 1810 32. La finalidad perseguida era separar los dos componentes principales de la miera, que son la esencia de trementina y la colofonia. Teóricamente, a presión atmosférica y a una temperatura de $160^{\circ} \mathrm{C}$, la esencia entra en ebullición, se separa en estado de vapor y puede ser condensada por refrigeración, permaneciendo en estado líquido a temperatura ambiente. La colofonia, que se mantiene estable hasta los $180^{\circ} \mathrm{C}$, se funde en el alambique y se solidifica al enfriar. En la práctica, sin embargo, era difí-

\footnotetext{
30 R. Xerica (1869), pp. 50-51.

${ }^{31}$ R. Sargos (1949), pp. 452-453, R. Xérica (1869), pp. 108-109.

32 R. Sargos (1949), p. 461-462.
} 
cil mantener la temperatura del proceso y evitar que el rendimiento y la calidad final de los productos se vieran mermados al superar los $180^{\circ} \mathrm{C}$. Inicialmente fue la adición directa de agua lo que, de forma muy rudimentaria, permitió mantener un cierto control de la temperatura en el sistema más primitivo de destilación conocido como a fuego directo. Con ello, no obstante, nunca podían conseguirse los mejores grados de colofonia y seguían existiendo importantes pérdidas de esencia, además de un mayor gasto de combustible y riesgos de explosión e incendio ${ }^{33}$. A mediados del siglo XIX, la industria francesa introdujo la destilación por el sistema mixto, en el cual el alambique se calentaba por fuego directo y a partir de una determinada temperatura se inyectaba vapor o agua líquida para tratar de mantener la temperatura dentro de los niveles más adecuados. El procedimiento, que se extendió con rapidez, reducía de forma significativa la duración del proceso y los consiguientes gastos de combustible, a la vez que permitía obtener productos de mayor calidad ${ }^{34}$. Hacia los años setenta, empezó a difundirse la destilación a vapor, donde el empleo directo del fuego es sustituido por el vapor de agua obtenido en un generador independiente e introducido en alambiques de nuevo diseño. En las nuevas instalaciones, más complejas y costosas, la temperatura se regulaba con mayor precisión, el tiempo empleado volvía a reducirse y se mejoraba la calidad de los productos. En torno a la primera guerra mundial, de nuevo un empresario landés, introdujo la destilación al vacio, cuya ventaja principal residía en reducir la temperatura de la destilación y la presión del aire, lo cual atenuaba la oxidación de la colofonia y su coloración ${ }^{35}$. Finalmente, a partir del sistema patentado en Francia por L. B. Castets (30 de junio de 1908) ${ }^{36}$, se consiguió que la destilación fuera un proceso continuo, de manera que las sucesivas cargas de miera podían ser introducidas en el alambique sin necesidad de esperar a la descarga de la colofonia ya obtenida. Al igual que en la destilación de otros productos (alcohol, bencina, etc.), el sistema continuo suponía un importante ahorro de tiempo, combustible y mano de obra, además de permitir la obtención de productos más uniformes y de mejor calidad ${ }^{37}$.

33 J. Iturralde, O. Elorrieta (1914), pp. 105-107; G. Dupont (1926), pp. 48-51.

it R. Sargos (1949), p. 500; J. Iturralde, O. Elorrieta (1914), p. 108.

${ }_{15}$ Ibídem. «En esta destilación se procura desprender la esencia sin alcanzar la temperatura de descomposición de la colofonia, a cuyo fin se inyecta vapor de agua, no para arrastrar el de esencia, sino para conseguir descender el punto de ebullición del aguarrás con arrego a la teoría de la destilación de las mezclas. Bien practicada la operación, y suponiendo el caso general para España, o sea el de realizarse a la presión ordinaria habremos volatilizado toda la esencia a temperatura inferior a $180^{\circ}$, a la que se inicia la descomposición de la colofonia. Ésta quedará en el alambique en estado líquido, y dándole salida al exterior, filtrándola, se recogerá en recipientes apropiados, donde se solidificará» (L. Vélaz Medrano, 1924, p. 486).

36 M. Vèzes, G. Dupont (1924), p. 266.

${ }^{37}$ G. Dupont (1926), pp. 55-56. 
Para concluir este apretado repaso a la evolución tecnológica del sector, es necesario referirnos a la situación creada a partir de principios del siglo XX con la creciente oferta de productos alternativos, calificados en ocasiones como adulterantes, pero que penetraron con fuerza en los mercados, desplazando a los originales en sectores básicos. El espectacular desarrollo de la industria química ya hacía entrever a fines del siglo XIX la posibilidad de que surgieran sustitutos capaces de amenazar los equilibrios básicos de la industria resinera tradicional. Sin embargo, tal posibilidad se presentó de forma más prematura de lo que algunos habían podido prever ${ }^{38}$.

Los primeros en desarrollarse fueron las colofonias y esencias de trementina obtenidas mediante nuevas técnicas de destilación de maderas resinosas. En realidad, se trataba de procedimientos que habian evolucionado lentamente en diferentes países europeos a partir de métodos practicados desde antiguo. Tal como hemos señalado anteriormente, en las zonas centrales y del norte de Europa, a pesar de disponer de grandes extensiones de bosque, razones climáticas impedían que la resina fuera obtenida de acuerdo con los sistemas descritos para la industria espanola, francesa o americana. En estas zonas, mediante la destilación seca de la madera se conseguían obtener alquitranes y esencias de trementina, aunque siempre de calidad muy inferior a la obtenida en la destilación directa de la trementina. En los EE.UU., tras haber destruido enormes extensiones de bosque en los estados del sudeste, a partir de $1909^{39}$ comenzó la explotación sistemática de los tocones y troncos de árboles muertos en las zonas de antigua resinación ${ }^{40}$, lo cual permitió un fuerte crecimiento en la producción de colofonias y esencias de madera, también de inferior calidad a las obtenidas por los sistemas tradicionales, pero con unos precios mucho más bajos. La destilación completa de la madera en los diferentes tipos de retortas que fueron introduciéndose tanto en Europa como en los Estados Unidos, implicaba, no obstante, temperaturas superiores a los $180^{\circ} \mathrm{C}$, lo cual no permitía

${ }^{38}$ En este sentido, el ingeniero encargado de la elaboración del Proyecto de Ordenación del Grupo Segundo de los montes de Segovia para el período 1895-1910, se expresaba con las siguientes palabras: «La resina es elemento de grande influencia industrial en el mundo, sirviendo de base a la fabricación de numerosos productos cada vez más extendidos y de mayor demanda. Claro es que algún dia la ciencia pudiera en sus prodigiosos descubrimientos de la Química hallar un sustituto a este producto en alguna de sus aplicaciones; pero no se entreve ni se alcanza el día en que esto pueda suceder y menos el de la posible y completa sustitución de una primera materia organizada de tan compleja composición y que tiene por laboratorio el organismo particular de muy contadas especies" (A.S.T.M.A.O.T., Segovia, Libro G-02/00).

${ }^{39}$ Fecha en la que se levantó la primera planta comercial para la obtención de productos resinosos conocidos en los EE.UU. como wood naval stores (J. Drew, 1989, p. 27).

40 «En Amérique, la matière première utilisée est le light-wood, parties très résineuses des troncs de longlealf-pine provenant de vieilles forêts gemmées inconsidérément par le vieux procédé du box-system» (G. Dupont, 1926, p. 166). 
mantener la estabilidad de la colofonia y, por consiguiente, existían dificultades adicionales para, posteriormente, purificar y rectificar los productos. Los citados inconvenientes fueron resueltos cuando la colofonia y la esencia de trementina pudieron ser obtenidos como subproductos de las grandes fábricas de pastas celulósicas al sulfato, conociéndose en el mercado como colofonia del tall-oil y aguarrás al sulfato, respectivamente. En este caso, el proceso, técnicamente vinculado a la industria papelera, se lleva a cabo en frío, mediante el empleo de disolventes químicos. Aunque la calidad seguía siendo inferior a la obtenida mediante el tratamiento clásico de la resina, los precios eran muy inferiores y existía la posibilidad de abastecer a la industria de forma estable y regular, rompiendo con la permanente incertidumbre que siempre había caracterizado al sector ${ }^{41}$. Las primeras iniciativas en este terreno se llevaron a cabo a partir de 1910 en los países escandinavos. Sin embargo fue a partir de 1949, una vez que la industria papelera americana empezó a procesar el tall-oil, cuando realmente se produjo un cambio radical en el mercado mundial de productos resinosos ${ }^{42}$. Por último, el desarrollo de la compleja industria petroquímica también aportó un sucedáneo que desde principios del siglo XX fue desplazando a la esencia de trementina sobre todo en la preparación de pinturas de baja calidad. Se trataba de un nuevo disolvente, conocido en el mercado como white-spirit, y que inicialmente se comercializó mezclado con la esencia de trementina, por lo que se consideró un producto fraudulento ${ }^{+3}$. Sin embargo, la diferencia de precios hizo que el white-spirit fuera una permanente amenaza para la esencia de trementina en los empleos directos menos exigentes en calidad ${ }^{44}$.

\section{LOS INICIOS DE LA MODERNIZACIÓN (1860-1890)}

La modernización de la industria resinera se inició en España mediado el siglo $\mathrm{XIX}$, en un proceso muy vinculado a la expansión y el cambio técnico que se estaban produciendo en la región francesa de Las Landas. Sin embargo, a pesar de que apenas tenemos referencias sobre las formas de explotación y aprovechamiento de la resina existentes en etapas anteriores, sabemos que los avances registrados en la segunda

11 F. Nájera y Angulo (1966), pp. 3312-3313.

12 Países industrializados como Suecia. Noruega, Finlandia, Canadá, Alemania, etc., con amplias reservas forestales y tradicionalmente compradores de productos resinosos, pudieron transformarse en exportadores, poniendo en peligro la industria resinera tradicional (I. Claver Farias, 1985, pp. 56-57)

${ }^{43} \mathrm{M}$. Tomen (1931); para la industria petroquímica ver K. Chapman (1991).

${ }^{4}$ «Ce white-spirit est parfois utilisé pour la fraude des essences mais plus souvent comme substituant complet ou partiel de l'essence de térébentine dans la confection des cirages, vernis, peintures, encaustiques, toiles cirées, etc.» (G. Dupont, 1926, p. 246). 
mitad del siglo XIX no arrancaban de cero. Una importante tradición industrial campesina, extendida en numerosas poblaciones de montaña de la meseta norte castellana, había precedido al establecimiento de nuevas técnicas, empresas e instalaciones.

En Segovia, provincia que siempre se ha mantenido a la cabeza del sector, localidades como Zarzuela del Pinar, Navas de Oro, Coca, Cuéllar, etc., distribuían entre sus vecinos «a precio módico» porciones de monte comunal o de propios, denominados matas o pegueras, compuestos por un número de pinos que oscilaba entre 500 y 2.000 . La resinación se efectuaba de acuerdo con el sistema denominado a muerte o pino perdido, siguiéndose los procedimientos que han sido descritos con anterioridad. Para el procesamiento, los mismos vecinos construían primitivos hornos de montaña (pegueras), compuestos por tres cavidades escalonadas y con revestimiento de barro o adobes donde obtenían pez negra y aguarrás ${ }^{45}$. De acuerdo con los datos recogidos por P. Madoz, uno de los renglones característicos de la producción en la localidad de Coca estaba compuesto por pez, aguarrás, resina, trementina e incienso, siendo la cuantía difícil de estimar por cuanto que «dependen de lo más o menos que se dedican a estraerlos segun los años»; existían aproximadamente treinta vecinos dedicados a la extracción de miera, que era posteriormente vendida a los fabricantes de aguarrás y a la obtención de pez. El procesamiento se llevaba a cabo en ocho fábricas, «vendiendo los productos resinosos para todos los $\cdot$ demas puntos del reino» ${ }^{46}$. En la localidad de Cuéllar, existían incluso cuatro destilerías municipales, que eran arrendadas en pública subasta, como pertenecientes a los propios del citado ayuntamiento, comercializando su producto en Castilla y Andalucía ${ }^{47}$. Zarzuela del Pinar tenía una población compuesta por vecinos que «siempre fueron resineros, y en tiempos antiguos fiaban casi exclusivamente su subsistencia a esta industria» ${ }^{48}$; mediado el siglo XIX, también según Madoz, contaba con «una buena fáb. de pez negra, con 7 homos para su elaboración: 4 para resina, aguarras, pez griega, trementina e incienso, y esportacion de la pez y demas producciones del pino para diferentes puntos» ${ }^{49}$.

De acuerdo con la información recogida por $\mathrm{C}$. Rodríguez, ingeniero de montes y hombre clave en la futura industrialización del sector, la primera destilería moderna para el procesamiento de la resina fue establecida por Pedro de Egaña en la localidad burgalesa de Hontoria del Pinar ${ }^{50}$. Aunque la fecha proporcionada por

45 A fines del siglo XviII en Segovia se producian de 33.000 a 34.000 arrobas de pez negra (C. de Lecea y García, 1897, p. 1901.

46 P. Madoz (1847), t. VI, p. 498.

47 C. de Lecea y García (1897), p. 190.

48 C. de Lecea y García (1897), p. 190.

49 P. Madoz (1850), t. XVI, p. 664.

${ }^{50}$ Memoria L.U.R.E. 1898 , p. 6. 
nuestro informante es 1848 , de hecho la nueva fábrica debió empezar su actividad con anterioridad. P. Madoz, en un volumen de su Diccionario editado en 1847 ya menciona la existencia en Hontoria de «una gran fábrica de materias resinosas» ${ }^{51}$. Por su parte, R. Xérica, en uno de los primeros trabajos publicados en España sobre la industria resinera, afirma que la fábrica de Hontoria fue establecida en 1843 para explotar los pinares de los montes públicos de Palacios, Bilviestre, Hontoria, San Leonardo, Santa María Muñecas y Espeja ${ }^{52}$. Posteriormente, se montaron nuevas fábricas en Hornillos (Valladolid) y Almansa (Albacete). El sistema empleado para la resinación seguía siendo a muerte y la destilación se efectuaba «de un modo imperfecto en las antiguas tinajas y pegueras o en las primitivas alquitaras» ${ }^{53}$. Al parecer, estos primeros establecimientos no lograron consolidarse debido a múltiples factores. La resinación a muerte y sus negativas consecuencias sobre el arbolado, motivaron la resistencia a la concesión de los aprovechamientos por parte de las autoridades e instituciones competentes en la materia. También se constató una «hostilidad de las gentes del país», posiblemente como respuesta a la pérdida de antiguos aprovechamientos vecinales. Finalmente, un mercado interior reducido y costosos e insuficientes medios de transporte fueron circunstancias igualmente negativas ${ }^{54}$.

Aunque no disponemos de información seriada que permita reflejar la trayectoria del sector durante esta etapa, en los años sesenta la industria resinera española conoció un importante período de expansión y cambio ${ }^{55}$. Al igual que estaba ocurriendo en la principal región productora del sudoeste francés, la paralización de los envíos de productos resinosos americanos hacia Europa debido al estallido de la Guerra de Secesión y el consiguiente bloqueo de los puertos exportadores, permitió a los productores nacionales la realización de extraordinarios beneficios. El inesperado incremento de precios y la expansión de la demanda se tradujo rápidamente en la aparición de nuevas empresas y la incorporación de las técnicas más avanzadas previamente difundidas en Las Landas, importándose de Francia «los métodos para verificar las labores de resinación y hasta los útiles para las mismas» ${ }^{56}$.

51 Además de la producción de resinas, la extracción de abundante madera de pino y la actividad de tres sierras, completaban una economía local muy centrada en la explotación de los recursos forestales (P. Madoz, 1847, t. IX, p. 223).

52 R. Xérica (1869), p. 127.

"Memoria L.U.R.E. 1898, p. 6.

${ }^{54}$ Memoria L.U.R.E. 1898 , p. 6.

5 «Muchos fabricantes han introducido de algunos años a esta parte grandes mejoras en sus establecimientos, cuyos aparatos han sido modificados y perfeccionados; de manera que este trabajo, abandonado hace poco tiempo a algunos obreros rutinarios, al presente puede decirse que marcha de una manera progresiva y racional» (R. Xérica, 1869, p. 59).

st A. Cid Ruiz-Zorrilla (1941), p. 69. 
La iniciativa empresarial de mayor importancia fue la emprendida por los hermanos Ernesto y Leopoldo Falcón que, junto con Ruiz y Llorente, constituyeron en 1862 la Sociedad Anónima La Resinera Segoviana, que posteriormente se transformaría en colectiva, bajo la denominación de Falcón, Ruiz y Llorente. Los hermanos Falcón, procedentes de Mont-de-Marsan, habían conocido con anterioridad los nuevos métodos empleados en la región francesa de Las Landas, tanto en lo referente a la extracción como a la elaboración de la miera, e introdujeron por primera vez en España la resinación a vida por el método Hugues ${ }^{57}$.

Como hemos visto, al igual que ocurría con las empresas citadas anteriormente, este nuevo establecimiento se ubicaba en una zona donde la resinación venía practicándose desde antiguo. En concreto, en la fecha en que La Resinera Segoviana dio comienzo a su actividad, existían en funcionamiento 11 fábricas de aguarrás, 16 de pez y 2 de resinas, en las localidades de Coca, Zarzuela del Pinar y Navas de Oro ${ }^{58}$. La sociedad obtuvo inicialmente la concesión oficial para la resinación de los pinares de Cantosal en Coca ${ }^{59}$, un privilegio de introducción de los nuevos métodos de resinación por espacio de cinco años ${ }^{60}$, estableciendo una primera fábrica en la localidad citada. Gracias a la extraordinaria coyuntura provocada por la Guerra de Secesión Americana, La Resinera Segoviana lograría consolidar su posición y ampliar los aprovechamientos en la extensa masa forestal existente al noroeste de la provincia de Segovia, realizando «pingües beneficios que la colocaron en situación ventajosísima para poder atravesar la época de crisis industrial, y contrarrestar las competencias que se presentaron más tarde» ${ }^{61}$. De este modo, aunque fue necesa-

37 «El adelanto, como se vé, fué de importancia. Por los medios antiguos, los pinos destinados a la resinación morían indefectiblemente: por el sistema moderno, si la resinación disminuye en algo el crecimiento del arbol, en nada afecta a la calidad de la madera, y los pinos resinados pueden vivir y viven después, y se reponen del jugo que se les extragera, siempre que se guarden los períodos de reposo o descanso que siguen a la extracción de la resina. Aunque el arbol padezca un tanto, como no puede menos de padecer, por el aprovechamiento de sus jugos vitales, siempre es infinitamente mayor la utilidad que produce, que lo que disminuye en crecimiento, y como el valor de la madera resinada se diferencia en poco del que alcanza la que no lo fue, viene a resultar un beneficio positivo de gran importancia, mejor dicho, un producto anual seguro a los municipios y a los particulares dueños de pinares que se deciden a resinarlos» (C. de Lecea y García, 1897, p. 192); ver, asimismo, M. Vèzes, G. Dupont (1924), p. 133.

58 C. de Lecea y García (1897), p. 190.

5" Se trataba de una masa de unos 40.000 pinos, entregados por espacio de cinco años «bajo el pliego de condiciones facultativas arregaladas a las enseñanzas de la ciencia, con el fin de que los pinos no sufrieran el deterioro consiguiente a los rutinarios procedimientos de la resinación antigua, ni las mieras perdiesen en cantidad y calidad por las filtraciones del suelo, donde antes se recogían, en vez del tarro, donde se recogen hoy, y por la evaporación de la esencia en su derrame natural por las tremendas aberturas que hacian al árbol, y por su contacto con las impurezas acumuladas sobre ellas por la lluvia y el viento, en el amplio recipiente de la tierra, al pie del mismo árbol» (C. de Lecea y García, 1897, pp. 191-192).

tor La Reforma Arancelaria (1890), t. III, p. 11.

6) Memoria L.U.R.E. 1898 , p. 7 
rio vencer importantes resistencias sociales ${ }^{62}$, a fines de los sesenta, La Resinera Segoviana era ya una empresa que empleaba cuarenta trabajadores y producía 240 toneladas anuales de productos de alta calidad ${ }^{63}$, obteniendo posteriormente numerosos reconocimientos internacionales en distintas Ferias y situándose en condiciones de competir «con ventaja en calidad y cantidad con los productos extranjeros» ${ }^{6+}$. El proceso expansivo continuó en los años setenta «merced a los elevados precios que alcanzaron estos productos (principalmente porque la guerra franco-prusiana paralizó en la nación vencida el movimiento comercial e industrial), que proporcionándonos grandes utilidades nos permitieron ensanchar nuestra esfera de acción, ampliando la resinación, aumentando el número de fábricas y mejorando los medios de fabricación, hasta el punto de que hoy producimos la mayor parte de los derivados de la resina» ${ }^{65}$.

En la misma coyuntura, tal como ha sido analizado por diversos autores, en España se abordó la reforma de la normativa que regulaba el conjunto de los aprovechamientos forestales ${ }^{66}$. A pesar de las indudables insuficiencias y limitaciones del nuevo marco legal, que, en lo relativo a la industria resinera, se pusieron de manifiesto en los años setenta, la administración logró configurar las bases normativas que permitieron la extensión y normalización del sector. El cambio, en cualquier caso, no fue tarea fácil, especialmente allí donde existían sistemas de explotación tradicionales profundamente arraigados en economías campesinas cuya subsistencia dependía en buena medida del libre acceso al bosque.

No obstante, con la penetración gradual de unos métodos de resinación mucho menos agresivos que los que se habían empleado hasta entonces y ante la posibilidad de incrementar la rentabilidad del bosque, obteniendo ingresos monetarios regulares y en aumento, municipios, comunidades y particulares, facilitaron la concesión de aprovechamientos en montes públicos y el arrendamiento de los privados. El número de empresas tendió a crecer en aquellas provincias donde existian predominantemente masas de pinus pinaster o pino marítimo, extendiéndose la actividad

62 «No se crea por esto, que los señores Falcón, Ruiz y Llorente encontraron liso y llano el camino que se propusieron recorrer, ni que los pueblos llamados en primer término a disfrutar de los beneficios, aceptaran buenamente las ventajas que se les ofrecian. La nueva industria sufrió ruda oposición por parte de los antiguos resineros que temían por su ruina, y, mas que por ellos, por la encarnizada enemiga que la envidia ruín, la maledicencia miserable, y los odios y rencores propios de las localidades pequeñas suscitan siempre contra todo lo nuevo, contra lo transcendental, por más que sea ventajoso, o contra lo que tiende a variar los sistemas, las costumbres o los usos inveterados, por útil y provechoso que sea el cambio» (C. de Lecea y Garcia, 1897, pp. 192-193).

${ }^{63}$ R. Xérica (1869), p. 127.

4. La Reforma Arancelaria (1890), t. III, pp. 11-12.

'6s La Reforma Arancelaria (1890), t. III, p. 16.

to Sobre la evolución de la moderna legislación forestal en España pueden verse los siguientes estudios: H. Groome (1989 y 1990), J. I. Jiménez Blanco (1991) y J. Gómez Mendoza (1992), pp. 219-234. 
en los montes de Segovia, Valladolid y, más tarde, en Guadalajara, Ávila, Murcia, Burgos, etc. ${ }^{67}$. De acuerdo con los datos facilitados por C. Rodríguez, sabemos que en 1868 Julio Touchard instaló una nueva fábrica en Olmedo (Valladolid). En 1871 la duquesa de Denia, viuda del duque de Medinacelli, abrió otra en Las Navas del Marqués (Ávila) «perfectamente instalada con todos los adelantos conocidos hasta entonces en este ramo industrial, siendo la primera en que se aplicó el vapor como auxiliar en la destilación» ${ }^{68}$. En 1879 la Sociedad Ramos Martin y Senovilla abrió otra fábrica en Cuéllar (Segovia), «instalada modestamente, pero organizada con verdadera inteligencia y conocimiento del asunto» ${ }^{69}$. En 1882 fue nuestro informante, el propio C. Rodríguez quien, «previo detenido estudio en la materia, hecho personalmente en Francia» ${ }^{70}$, estableció una fábrica en Mazarrete (Guadalajara). La citada fábrica fue montada con «los aparatos y procedimientos de fabricación que se consideraron más prácticos y convenientes de los seguidos en Las Landas y que se han ido mejorando en vista de las enseñanzas de la práctica y de un constante estudio de las diversas operaciones y manipulaciones que constituyen esta industria, $\tan$ sencilla al parecer, pero que requiere una atención exquisita» ${ }^{71}$. Por las mismas fechas, Alejandro Basanta estableció una fábrica en Avilés, que tuvo una corta existencia debido al «escaso rendimiento que dan de miera los exuberantes pinos de la fértil costa de Galicia y Asturias (apenas 2 kilos por árbol) y de que, sin duda, por causas meteorológicas, los productos secos no igualan en blancura a los de las mieras de la región castellana» ${ }^{72}$. En 1887 el duque de Uceda instaló una fábrica en Nogarejas (León), «donde se han venido elaborando los productos de sus montes

6i «Vencidas, como decimos, por La Resinera Segoviana las resistencias que en un principio se la opusieron, esto es, persuadidos los pueblos de que el sistema por aquella sociedad planteado era mejor y más productivo que el antiguo, no solo fueron cediendo de su sistemática oposición, sino que al fin y al cabo se acogieron, en su inmensa mayoría, a los procedimientos de la Resinera, y se allanaron al método moderno, y facilitaron la resinación, conforme a él, de numerosos pinares (...).

Merced al buen concierto logrado entre los pueblos, los particulares y los fabricantes, son muchos centenares de miles de pinos los que se resinan por el sistema moderno; los municipios consiguen hoy un ingreso doce o catorce veces mayor que el que antes tenían, sin grandes perjuicios para los árboles; los propietarios que antes no lograban, por lo general, provecho alguno de la resina, hacen contratos para el aprovechamiento de muchos millares de pinos por cierto número de años, asegurando muy buenas rentas; los jornaleros de la estensísima zona pinariega encuentran trabajo con más facilidad, por el gran desarrollo de esta industria; los dueños de carros dedicados al transporte le hallan también para ellos y para sus yuntas; y la comarca toda, a donde estiende su radio de acción La Resinera, disfruta, de un modo o de otro, el inmenso beneficio de un manantial de dinero corriente que remedia infinitas nece sidades» (C. de Lecea y García, 1897, pp. 194-195).

${ }_{68}$ Memoria L.U.R.E. 1898, p. 9.

${ }^{69}$ Ibidem.

${ }^{70}$ C. Rodríguez (1908), p. 9.

${ }^{71}$ Memoria L.U.R.E. 1898 , p. 9.

72 Ibidem, pp. 9-10. 
que existen contiguos a la misma, cuya instalación está bien entendida y es adecuada a la importancia de las resinas que está destinada a elaborar» ${ }^{73}$. Más tarde, Sánchez y Cía. establecieron otra fábrica en Cuéllar (Segovia), «en la que se elaboraban productos muy aceptables» ${ }^{74}$. Falcón, Ruiz y Llorente, en 1892 instaló una nueva fábrica en Arévalo (Ávila), «estando perfectamente instalada, últimamente con aparatos de destilación a vapor solo y obteniéndose productos muy aceptables» ${ }^{75}$. Además de las señaladas, se implantaron otras destilerías de más modestas dimen. siones, sobre todo en Segovia, «que no han podido prosperar, contribuyendo no obstante a la encarnizada competencia que en los últimos años ha existido entre los fabricantes grandes y chicos de las provincias de Valladolid, Ávila y Segovia para la adquisición de aprovechamientos de resinas» ${ }^{76}$.

Pese a la multiplicación de instalaciones y nuevas sociedades, y el incremento de los aprovechamientos, la expansión del conjunto del sector se vio pronto amenazada por problemas arancelarios y de estructura empresarial. En los años ochenta la industria resinera española debió enfrentarse a las consecuencias de la rebaja arancelaria pactada con Francia en el acuerdo comercial de 1879. A pesar de las protestas de los industriales de la resina, compensando, posiblemente, las mejoras conseguidas para el acceso del vino español al mercado francés ${ }^{77}$, los derechos de entrada en España de las resinas procedentes de Las Landas se rebajaron de 2,30 pts. por $100 \mathrm{~kg}$ a tan sólo $41 \mathrm{cts} .^{78}$. Por su parte, las colofonias españolas pagaban a su introducción en Francia 2 pts. por $100 \mathrm{~kg}^{79}$. La modificación tuvo inmediatas consecuencias, pues la región landesa, con un cómodo acceso a los mercados por vía marítima a través de Burdeos y Bayona, estaba en condiciones de situar las resinas francesas en la mayor parte de los puertos españoles a precios inferiores a las procedentes del interior de Castilla. En este sentido, la producción española siempre tuvo que vencer la desventaja de unos elevados costes de transportes de una industria ubicada mayoritariamente en el centro peninsular y unos mercados que se situaban en la periferia ${ }^{80}$. A pesar de que los fabricantes españoles que habían

73 Ibidem, p. 10.

74 Ibídem.

75 Ibidem.

76 Ibidem.

77 Lo cual sería un claro ejemplo de que «Como contrapartida de las exportaciones vinícolas, el país tuvo que abrir la puerta a las manufacturas extranjeras» (J. Nadal y C. Sudrià, 1993, p. 217). Sobre el régimen de acuerdos comerciales de la época, ver J. M. Serrano Sanz (1987).

${ }^{78}$ Memoria L.U.R.E. 1898, p. 11.

${ }^{74}$ La Reforma Arancelaria (1890), t. III, p. 9.

81) «Las consecuencias fueron tan desastrosas como previstas y bien pronto pudieron convencerse los industriales españoles de que era imposible toda competencia con el producto francés transportado como era, por vía marítima desde Bayona y Burdeos a Bilbao, Santander, Coruña, Sevilla, Málaga, Barcelona y demás puertos de nuestras costas en donde radica su principal consumo, por un flete insig- 
modernizado sus instalaciones podían, a su juicio, producir «mejor y más barato al pie de fábrica» ${ }^{81}$, las deficiencias y carestía del transporte interior reducían su competitividad frente a franceses y americanos ${ }^{82}$. Aunque no disponemos de indicadores que nos aproximen a la marcha del sector durante los años que siguieron a la liberalización arancelaria pactada con Francia, todo parece indicar que los efectos fueron importantes, no tardando en aparecer stocks acumulados en los almacenes de numerosas resineras ${ }^{83}$.

Por otro lado, junto a las dificultades de acceso al mercado de productos finales, los empresarios también tuvieron que enfrentarse a la intensificación de la competencia en la adquisición de la materia prima ${ }^{84}$. Tal como hemos visto, la normativa aprobada en la primera mitad de los sesenta permitió normalizar el acceso a una gran masa forestal que a pesar de las desamortizaciones permaneció en manos de los municipios ${ }^{85}$, lo cual fue decisivo desde el punto de vista del desarrollo y la extensión de la actividad resinera. Sin embargo, bajo el régimen de subastas establecido en el reglamento de 17 de mayo de 1865, los aprovechamientos de montes públicos concedidos a particulares afectaban generalmente a pequeñas extensiones y tenían plazos de cinco años, lo cual se adecuaba con dificultad a las necesidades de crecimiento de una industria para cuya actividad era necesario garantizar el acceso a la materia prima en condiciones de mayor estabilidad. Por otra parte, la resinación tal como empezó a practicarse a partir de la implantación del método Hugues en los

nificante que tenía a su favor una diferencia de 25 a 50 pesetas por tonelada, comparado con los precios de transporte que costaba el nacional desde los puntos de producción situados forzosamente en el centro de la Península donde se hallan las masas de pinares» (Memoria L.U.R.E. 1898, pp. 11-12).

${ }^{81}$ La Reforma Arancelaria (1890), t. III, p. 7.

82 «Nuestros mercados son principalmente Cataluña, las Provincias Vascongadas y Andalucía. Del Norte-América sabido es que los transportes son muy baratos, hasta el punto de poder fijarse a la tonelada, por término medio, 6 pesetas, que en casos extraordinarios llega a 10.

Las Landas francesas mandan sus productos secos a todo el Norte de España con menos recorrido, y puede tomarse, como tipo medio de coste de transporte, 18 pesetas, y a nosostros nos cuesta de 45 a 55 pesetas. De forma que hay una diferencia notable en contra, por esta sola circunstancia, de 35 a 45 pesetas en tonelada» (La Reforma Arancelaria, 1890, t. III, p. 7).

${ }^{83}$ Tal como se indica en la memoria justificativa del Plan de Aprovechamientos de los montes de Segovia correspondiente al año forestal 1888-1889, se descartó ampliar las resinaciones dado «el escaso movimiento observado en las fábricas resineras, en donde existen almacenados gran parte de los productos de las campañas anteriores, y por lo tanto a la deficientísima demanda que por parte de ellas hay de las primeras materias, o sean de las mieras» (A.M.A., Montes, 70/6).

${ }^{84}$ «Los precios alcanzados en las subastas van siendo mayores cada año, efecto de competencias entre varios fabricantes y aun por otras personas poco conocedoras de esta industria, que acceden a las licitaciones con fines más o menos censurables, pues no contando con capitales reconocidos ni aun con aptitud para la fabricación de productos, ofrecen la primera materia (si se les llega a adjudicar a cualquier precio la subasta) a fabricantes de otras provincias limítrofes si no se aceptan sus ofrecimientos por las del país» (A.M.A., Montes, 60/6, 1886-1887).

${ }^{85}$ F. Simón Segura (1973), pp. 218-224; véase, asimismo, el reciente trabajo del G.E.H.R. (1994). 
años sesenta, también requería planificar los aprovechamientos de forma más sistemática y en ciclos más largos. La creciente competencia en las ventas y la lucha entablada en las subastas y arrendamientos de los pinares que debían asegurar el suministro de la materia prima, acabaron provocando el cierre de las pequenas destilerías y el descenso de la actividad en numerosas fábricas ${ }^{86}$.

Dada la estructura del sector, la integración de las fases forestal e industrial, armonizando diferentes intereses y estrategias, fue una dificultad permanente cuya resolución se intentaría en distintas ocasiones sin demasiado éxito ${ }^{87}$. En las circunstancias indicadas, disponer de un patrimonio propio suficientemente extenso, era la única vía para escapar de la servidumbre que implicaba mantener una actividad industrial dependiente de inciertas subastas y arrendamientos. De hecho, únicamente los establecimientos mejor ubicados, con las mejores instalaciones y, sobre todo, aquellos que podían explotar montes propios, consiguieron evitar el cierre durante los difíciles años ochenta ${ }^{88}$. Por lo demás, las dificultades del sector acabaron forzando un amplio proceso de integración horizontal que agruparía a las empresas mejor establecidas y equipadas.

\section{EXPANSIÓN INDUSTRIAL Y CONCENTRACIÓN EMPRESARIAL: LA UNIÓN RESINERA ESPAÑOLA (1890-1913)}

La iniciativa partió de C. Rodríguez, propietario como hemos visto de una moderna fábrica en Mazarrete fundada en 1882. Sus primeras gestiones, tal como él

* «Con aprovechamientos de pinos en cantidades pequeñas, y plazos de cinco años, no era posible constituir Sociedad alguna de base fija y rendimiento seguro. Tal era la existencia de esas fábricas: vida lán guida y además, ruda competencia que las abocaba a inmediato trance de ruinas (C. Rodríguez, 1908, p. 13).

${ }^{87}$ Los problemas rebasaban el estricto ámbito de la producción, planteando dificultades de orden fiscal a la hora de distribuir cargas cuando, como ocurría con frecuencia, el industrial trabajaba sobre montes arrendados: «la producción abarca dos fases: la forestal y la industrial, la primera de las cuales comprende desde los trabajos preparatorios del pinar hasta el ingreso de las mieras en la fábrica y la segunda desde este momento hasta terminar el proceso de la elaboración de los productos que se derivan inmediatamente de la destilación (...), ambas fases formaban un ciclo de producción por confundirse en una misma persona la ejecución de los trabajos de una y otra y en tanto que el propietario del pinar era un mero arrendador de sus bienes que contribuía pasivamente a la explotación, el arrendatario ejecutaba los trabajos forestales y se ocupaba de destilar las mieras que en aquellos obtenía, de tal modo que los beneficios logrados con la venta de los productos correspondían al conjunto de sus actividades pero indudablemente una parte de ellos provenían de la explotación forestal y otra de la actividad industrial» (A.H.P.V., Hacienda, H. 963).

${ }^{88}$ «Antes del año 1882, existian nueve fábricas de diferente importancia, de las cuales se han cerrado tres, y de las otras seis, han cambiado dos de dueños, por las grandes dificultades que encontraban en su desenvolvimiento y porque exigen capitales considerables en relación con sus utilidades. Además han desaparecido muchas de las llamadas pegunas a virtud de la promulgación de las leyes que prohiben la resinación a muerte» (La Reforma Arancelaria, 1890, t. I, p. 195). 
mismo nos lo relata, se llevaron a cabo en 1885 , dirigiéndose personalmente a los propietarios de las fábricas de Valladolid y Coca con la propuesta de «llegar a una unión industrial y mercantil de los fabricantes, mediante la cual cesara la competencia que sostenían entre sí y se aunaran todos los esfuerzos para la mutua defensa» ${ }^{x y}$. El objetivo último del proyecto, perfectamente explicitado por su promotor, era lograr «una regularización industrial que, a la par que mejorase las condiciones de adquisición de la primera materia y las de fabricación y ventas, preparase y consiguiese, por armónico esfuerzo, un más amplio mercado, bastante a absorber la creciente producción, ya que estaba saturada con exceso la modesta demanda en que forzosamente habíamos de encerrarnos, trabajando, no sólo aislada, sino encontrada y reñidamente» ${ }^{90}$. Sin embargo, a pesar de los esfuerzos realizados por nuestro empresario, el proyecto tuvo que ser momentáneamente abandonado «después de muchas y asiduas gestiones, convencido de lo imposible que era, por aquel entonces poner de acuerdo a ambas casas, por la enemistad que entre ellas existía, a consecuencia de la encarnizada concurrencia que venían sosteniendo hacía algún tiempo en la adquisición de primeras materias y en la venta de productos» ${ }^{91}$.

En 1888, debido a la caída coyuntural de la producción en los Estados Unidos y Francia, los precios internacionales de la esencia de trementina experimentaron un inesperado incremento, del que los productores españoles, con una industria excesivamente fragmentada, no pudieron beneficiarse ${ }^{92}$. En la misma fecha, la fábrica de Valladolid sería adquirida por E. Gutiérrez, circunstancia propicia para tratar nuevamente de establecer algún tipo de acuerdo entre los productores. La iniciativa seguía estando en manos de C. Rodríguez, quien «después de una peregrinación por las fábricas», mediado el año 1888 logró reunirse en Madrid con el nuevo propietario de la fábrica de Valladolid, A. Basanta, dueño de una fábrica en Avilés y un representante de la antigua sociedad Falcón, Ruiz y Llorente establecida en Coca. En dicha reunión se establecieron unas bases de acuerdo que pocos días después serían ratificadas en un encuentro celebrado en Coca, constituyéndose un sindicato para la venta de aguarrás entre las fábricas de Valladolid, Coca, Mazarete y Avilés, que empezaría a trabajar bajo la razón social de La Unión Resinera Española, al cual se agregarían con posterioridad la fábrica de Nogarejas (León),

${ }^{89}$ C. Rodríguez (1908), p. 9.

4) C. Rodríguez (1908), p. 9.

9i Ibídem.

92 «A causa de la escasa producción habida en Francia y en los Estados Unidos, el aguarrás había llegado a adquirir en los mercados de Europa elevadísimos precios, no vistos hacía muchísimos años, de los que no se aprovechaban los fabricantes españoles ensañados en su ciega competencia» (Memoria L.U.R.E. 1898 , p. 13). 
perteneciente al duque de Uceda, y la de Cuéllar, que pertenecía a la sociedad Ramos y Mesón ${ }^{93}$.

Ciertamente, tal como afirma su promotor, desde el punto de vista de la organización empresarial, el acuerdo resultaba innovador, pues «fue éste sino el primero, uno de los primeros conciertos celebrados en España entre fabricantes del mismo producto, a que nos inclinó, a más del propio juicio sobre sus ventajas, las ya conocidas en los Estados Unidos de América, Inglaterra y Alemania como resultado de esta gran amplitud de la forma societaria, en su apogeo hoy, y una de las más eficaces del prodigioso desarrollo industrial de estas naciones, en el que, dueñas del mundo, descansan su fuerza y poderío» ${ }^{94}$. Los efectos de la integración, como veremos, no tardaron en hacerse notar, y la industria resinera española pudo recuperar el mercado interior y, a través de L.U.R.E., abordar con éxito su integración en el mercado internacional.

Constituido el sindicato, la tradicional competencia en las subastas por la adquisición de los aprovechamientos forestales quedó mucho más limitada, lo cual permitió abaratar los precios de la materia prima. El nuevo grupo de presión logró una revisión al alza de los aranceles vigentes ${ }^{45}$ y una reducción de las tarifas en el transporte ferroviario. Los precios interiores se incrementaron de forma muy sustancial y se reconquistó un mercado que desde los años setenta había sido penetrado por los productos franceses. En la exportación, se evitó la intermediación de las casas comerciales de Bayona y Burdeos, que hasta entonces revendian el producto español como si se tratara de francés, y se pudieron reducir los gastos de distribución, reestructurando las ventas y consiguiendo mejoras en los fletes. De este modo, los productos españoles, especialmente el aguarrás, lograron consolidar su presencia en los principales mercados europeos de Alemania, Bélgica, Italia y Centro-Europa ${ }^{\%}$.

${ }^{43}$ Memoria L.U.R.E. 1898 , p. 13.

${ }^{4}$ Memoria L.U.R.E. 1898, p. 13 . Años más tarde, una vez que C. Rodríguez, debido a desacuerdos habidos durante su gestión, fue apartado del cargo de director gerente de L.U.R.E., recordaría con indisimulado orgullo y no poco resentimiento, que «El pensamiento y trabajos para la constitución de La Unión Resinera Española fueron exclusivamente obra mía, teniendo que vencer no pocos obstáculos y sobrellevar no corta peregrinación para aunar voluntades, suavizar asperezas y armonizar dualismos poco menos que irreductibles, allanando en suma, todos los inconvenientes anexos a la magna obra de armonización económica que implica la realización de esta Sociedad como fuente de riqueza en un país en el que, no solamente no se habian acometido empresas semejantes de unificación industrial hasta bastantes años despues, sino que, a aquellas fechas, permanecian totalmente desarticuladas y en estado de lamentable atraso e impotencia los embrionarios elementos industriales que, en corto número, además, por entonces subsistían» (C. Rodríguez, 1908, p. 8).

"En 1892, al renovarse el anterior tratado comercial con Francia se estableció un derecho de entrada para el aguarrás francés de 10 pesetas por $100 \mathrm{~kg}$ y de 4,5 pesetas por $100 \mathrm{~kg}$ para la colofonia, «en virtud de lo cual comenzó a progresar de un modo ostensible la industria resinera en España» (A. Cid Ruiz-Zorrilla, 1941, p. 14).

\%6 Memoria L.U.R.E. 1898 , pp. 13-14. 
Desde el punto de vista normativo, los cambios fueron igualmente decisivos. La incapacidad administrativa del Estado y la presión ejercida por los industriales de la madera, el corcho y la resina, dieron lugar a la aprobación de un nuevo marco legal en el que las compañías explotadoras accedían al monte público en condiciones enormemente ventajosas. La introducción del sistema de ordenaciones en 1890 , la posibilidad de que fueran particulares quienes elaboraran los correspondientes estudios, el derecho de tanteo reconocido en las subastas a los concesionarios de los estudios y la ampliación del periodo de disfrute a veinte años, mejoraron ostensiblemente las condiciones de acceso a la explotación de los montes públicos, sobre todo para los empresas de mayores dimensiones, lo cual fue percibido de inmediato por los principales industriales del ramo ${ }^{47}$. Evidentemente, en la nueva situación y dado el comportamiento de los precios a lo largo del período, se estaban sacrificando los intereses de las entidades propietarias de monte público, sobre todo los municipios, en beneficio del sector transformador ${ }^{98}$.

Los logros observados tras los acuerdos pactados en Coca y la exitosa gestión llevada a cabo por el sindicato, tanto en el área estrictamente productiva y mercantil, como en la defensa de sus criterios e intereses frente a la administración, aconsejaba llegar a una forma de integración más estable. En 1896 y 1897, C. Rodríguez, principal impulsor de la iniciativa, ya había propuesto con claridad la conveniencia de una «completa fusión de intereses y capitales (...) como la única solución y medio definitivo de consolidar el negocio» ${ }^{99}$. Aunque en un principio la idea fue mal acogida, el acuerdo fue finalmente adoptado en una reunión celebrada en Madrid a fines de 1897, y se formalizó el 20 de enero de 1898, según escritura otorgada ante F. Hurtado de Saracho. A propuesta de C. Rodríguez, Bilbao fue la capital elegida para ubicar la sede social de la empresa, «por las salientes ventajas, que creo ocioso exponer, que a una Sociedad anónima ofrecía entonces dicha plaza» " ${ }^{100}$. Sin duda, las

${ }^{97}$ «Las cosas variaban por completo con las concesiones de estudios de ordenación. En la ley de 1890 había un germen de negocio que, después de percibido, era necesario realizar, llevar a la práctica», «por los beneficios que otorgaba a particulares concesionarios de estudios o proyectos de ordenación, siendo los más esenciales el aprovechamiento por el plazo de veinte años, y derecho de tanteo en la subasta» (C. Rodrígue $z, 1908$, pp. 13 y 24). Sobre los aspectos normativos de mayor incidencia en la modernización de la explotación forestal puede verse, J. I. Jiménez Blanco (1991) y J. Gómez Mendoza (1992).

${ }_{98}$ «Las concesiones por períodos largos obtenidas por el derecho de tanteo permitieron, por la estabilización del precio del producto en el monte, la formación de Sociedades y Compañias explotadoras de montes de mayor solvencia que las existentes; (...) pero la concesión que se hizo del derecho de tanteo al autor del proyecto de ordenación, lo que siempre lleva una limitación en el número de licitadores de las subastas, fue causa de que se arrendaran los montes a precios muy bajos, que habian de sostenerse por veinte años. (...) Con ello se beneficiaron grandemente algunos industriales, pero se perjudicaron mucho los propietarios de montes» (Anónimo, 1931, p. 5).

99 Memoria L.U.R.E. 1898 , p. 15.

C. Rodríguez (1908), p. 13. 
ventajas eran de diferente naturaleza, siendo las fiscales especialmente significativas bajo un régimen de Conciertos Económicos que permitió implantar un sistema tributario mucho menos gravoso para las empresas registradas en las Provincias Vascongadas, incluso para aquellas, como L.U.R.E., cuya actividad productiva se realizaba fuera del espacio territorial vasco ${ }^{101}$. Por otro lado, puesto que en el ánimo de los promotores estaba emprender una política de rápida expansión de la Sociedad, el interés por la captación de nuevos capitales dispuestos a ser integrados en la empresa también fue un criterio importante. Bilbao, una de las plazas financieras más dinámicas del momento, con una abundante oferta de capital acumulado en el sector minero y siderúrgico, era sin duda el lugar apropiado. La propuesta fue aceptada por Plácido Allende, Enrique Aresti y Víctor Chávarri, «primeras y únicas personalidades financieras a quienes nos dirigimos con tal fin, cuyo excelente golpe de vista y mucha práctica en toda clase de asuntos mercantiles, nos facilitó en gran manera la terminación del nuestro» ${ }^{102}$. Finalmente, La Unión Resinera Española, S. A., se constituyó con la participación de los antiguos empresarios resineros Falcón, Ruiz y Llorente, J. J. Gutiérrez, C. Rodríguez y los capitalistas más arriba mencionados. A partir de entonces, la modernización y expansión de la nueva empresa y el crecimiento del sector en su conjunto, permitieron que la industria resinera española fuera a principios del siglo Xx la tercera en importancia a nivel mundial, tras los Estados Unidos y Francia, orientando a la exportación una parte sustancial de sus productos básicos ${ }^{103}$.

Una vez formalizada la constitución de la sociedad, a propuesta de quien fue su director gerente hasta 1908, C. Rodríguez, se realizaron reformas inmediatas en las instalaciones y maquinaria de las fábricas en ella integradas ${ }^{104}$. Las nuevas dimensiones de la empresa también permitieron introducir cambios en su estructura organizativa, mejorando los sistemas de distribución de la materia prima entre las dife-

101 Con la renovación y reforma del Concierto de 1894 llevada a cabo en 1900, se estableció dejar fuera del citado régimen a las Sociedades y Compañías que se constituyan para explotar industrias fueaunque «para evitar perjuicios a las sociedades constituídas hasta la fecha, se ha procurado dejarlas a salvo y que la declaración alcance sólo a las que se constituyan en lo sucesivo» (N. Vicario y Peña, 1909, pp. 306-307). Posteriormente, de acuerdo con las Reales órdenes de 25 de junio de 1909 y 22 de marzo de 1920, las sociedades y compañias formadas en el País Vasco antes de la promulgación de la ley de 27 de marzo de 1900, estaban exentas del impuesto de utilidades por los (1, 2,3 y 4 de la tarifa 3." (A.H.P.V., Hacienda, H. 962). Sobre la privilegiada situación fiscal de las empresas vascas bajo el régimen de Conciertos Económicos, ver E. J. Alonso Olea (1993).

102 Memoria L.U.R.E. 1898 , p. 15.

${ }^{103}$ Con datos referidos al período $1910-1913$, España exportaba en torno al $63 \%$ de la esencia y el $45 \%$ de la colofonia ( $R$. Uriarte, en prensa).

${ }^{104}$ Las reformas e innovaciones afectaron a las fábricas de Arévalo, Valladolid, Coca, Nogarejas, Mazarete y Almazán (Memoria L.U.R.E. 1898, pp. 16-17). 
rentes fábricas, con una economía en los transportes y un mayor rendimiento en la miera tratada. Por otro lado, aunque L.U.R.E. se había situado en una posición absolutamente privilegiada, en algunas zonas, sobre todo en las principales áreas resineras de Segovia, seguía existiendo una importante competencia en las subastas, por lo que era necesario solucionar «el doble problema de adquirir sin lucha dichos aprovechamientos vencidos y de evitar toda concurrencia en la venta de los productos» ${ }^{105}$. Tras diversas gestiones, se logró un contrato de compra de las fábricas de Ramos y Mesón y la de Sánchez y Cía. con importantes aprovechamientos en Cuéllar, con lo cual se eliminaban dos de las empresas que no habían entrado a formar parte de L.U.R.E., «quedando así resueltas radicalmente dichas dificultades y consolidados completa y definitivamente los elementos que constituyen esta Sociedad» ${ }^{106}$. La estrategia monopolista y de expansión perseguida por la sociedad, le llevó a la creación de nuevas fábricas allí donde pudieran existir masas de pinos susceptibles de ser resinados en condiciones de rentabilidad. De este modo, hacia 1920 L.U.R.E. tenía un total de 25 fábricas propias, distribuidas en 14 provincias ( 3 en Segovia, 4 en Ávila, 2 en Guadalajara, 2 en Burgos, 1 en Soria, 3 en Cuenca, 1 en Cáceres, 1 en Granada, 1 en Valladolid, 1 en León, 1 en Castellón, 1 en Málaga, 1 en Madrid, 1 en Teruel y 1 en lugar que no ha podido ser determinado), lo cual le permitía procesar en torno al $60 \%$ de la miera obtenida en España ${ }^{107}$.

Elemento estratégico fundamental en esta política expansiva fue la ampliación del patrimonio forestal. Aunque el régimen de ordenaciones establecido a partir de 1890 mejoró las condiciones de acceso a los montes públicos, el sistema de subastas, en la medida en la que permitía la penetración de nuevos empresarios en el sector, seguía siendo insuficiente para sostener con garantía la actividad de una empresa de las dimensiones y objetivos de L.U.R.E. De hecho, a pesar de su indiscutible posición hegemónica, con la extensión de la actividad y la aparición de nuevas empresas rivales, la pérdida de aprovechamientos en subastas era un permanente riesgo que podía desestabilizar la marcha de determinadas fábricas. Por ello, especialmente durante sus dos primeras décadas de funcionamiento, L.U.R.E. trató de mejorar las condiciones de acceso a la materia prima incrementando constantemente su patrimonio, mediante la adquisición de diferentes fincas que dotaron a la Sociedad de una base segura y permanente ${ }^{108}$. De este modo, hacia 1920 ,

105 Memoria L.U.R.E. 1898, p. 18.

${ }^{106}$ Memoria L.U.R.E. 1898 , p. 18.

107 M. Vèzes, G. Dupont (1924), p. 276.

108 «No encontramos otra solución eficaz (...), que adquirir una base permanente de explotación, independiente de la formada por los contratos de aprovechamientos forestales de montes del Estado o de los Municipios que sólo pueden obtenerse por subasta pública y por consiguiente de libre licitación» (Memoria L.U.R.E. 1905, p. 29). 
L.U.R.E., con un patrimonio forestal cercano a las 70.000 hectáreas, podía afirmar que era «propietaria casi seguramente después del Estado, de mayor extensión de patrimonio forestal que ninguna otra persona o entidad» ${ }^{109}$. Ello no impidió que la empresa explotara amplísimas extensiones de monte público y arrendado a particulares. Aunque, por el momento, sólo disponemos de cifras tardías, tal como puede comprobarse en el Apéndice 2, en los años 1928-1933 en torno al 50\% de los pinos resinados por L.U.R.E. eran públicos.

\section{GRÁFICO 1}

Número de pinos en resinación, 1898-1933

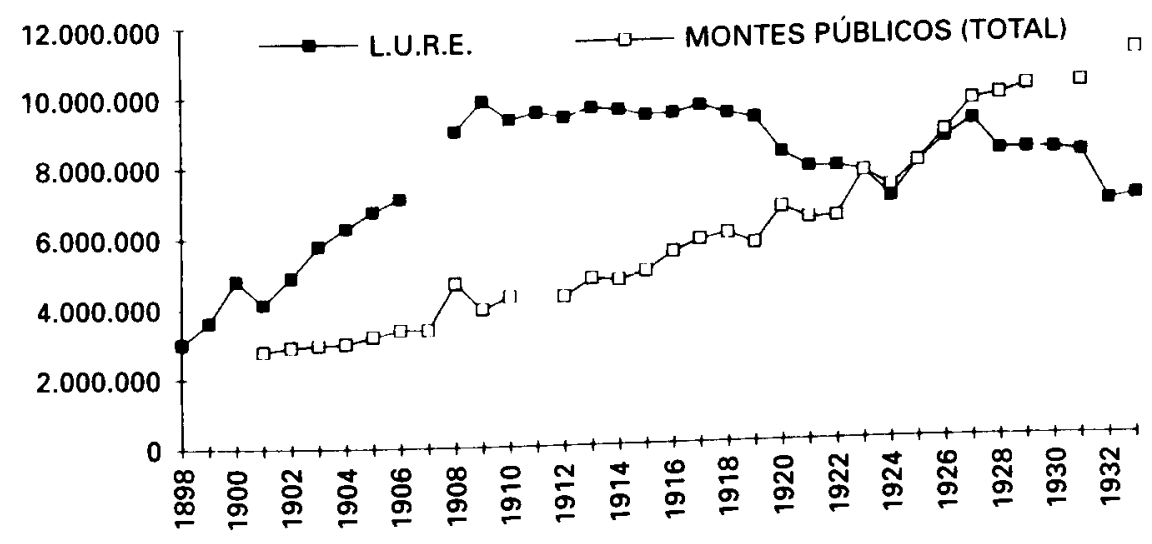

FUENTE: Apéndices 1 y 2.

La constitución de L.U.R.E. en 1898, desde el punto de vista del comportamiento del mercado, tuvo lugar en un momento de crisis industrial y contracción del mercado interior. El negativo impacto de la pérdida de las Antillas y Filipinas, mercados sobre los que la industria textil catalana había trasladado una parte significativa de sus ventas desde los años ochenta ${ }^{110}$, redujeron uno de los más importantes espacios de consumo ${ }^{111}$. La industria jabonera también redujo el consumo de colofonias, en este caso debido a que la elevación de los tipos de cambio de la peseta encareció la compra en el exterior de los aceites, sobre todo de coco, empleados

lus Memoria L.U.R.E. 1921-1922, p. 5.

1111 C. Sudrià (1983), pp. 371-376.

11 «Como no podía menos de suceder, las ventas en la Península se han resentido notablemente de las aciagas circunstancias porque ha atravesado el país y de la crisis industrial que la pérdida de las Antillas y de Filipinas ha producido en Cataluña, que es el mercado más importante para nuestros productos» (Memoria L.U.R.E. 1898, p. 23). 
para la fabricación de los jabones blandos, lo cual estimuló «la fabricación de otros jabones a base de silicato, sebo, orujo, y otras grasas empleadas este año por los jaboneros con preferencia a los antedichos aceites» ${ }^{112}$.

La contracción del mercado interior trató de ser compensada mediante un incremento de la presencia en los mercados europeos ${ }^{113}$. De hecho, la orientación exportadora de la empresa, basada en la acreditada calidad de sus productos, era la única posibilidad de expansión para una industria cuya capacidad productiva excedía con creces las posibilidades de absorción del mercado interno ${ }^{114}$.

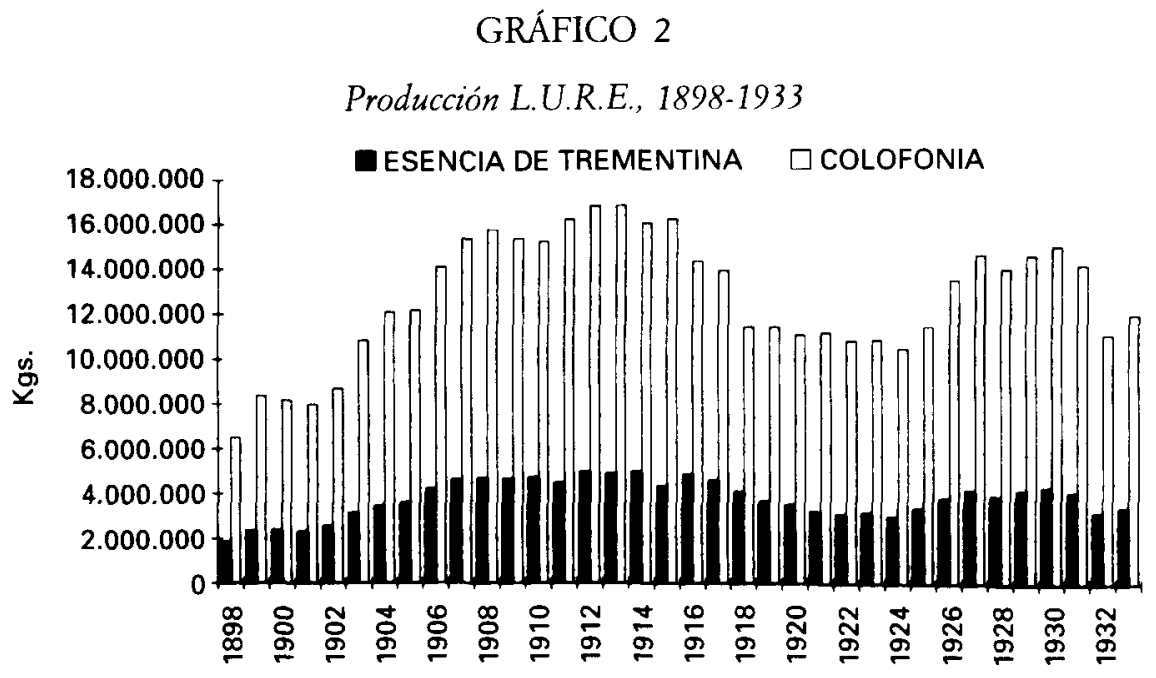

FUENTE: Apéndice 3.

El primitivo sindicato había concertado sus ventas en el exterior con la casa Speth y, desde su constitución, había llevado a cabo un importante esfuerzo por ampliar la presencia en mercados exteriores, principalmente en Alemania y Bélgica. En 1898 se entró en contacto con la casa Levita, de Amberes, logrando mejores condiciones y una mayor facilidad de acceso al mercado. Simultáneamente, también se remi-

112 Memoria L.U.R.E. 1898, p. 23.

113 «La falta de ventas era aún mucho mayor en el aguarrás, por todo lo cual y ante los temores de perturbaciones en la Peninsula, tuvimos que preocuparnos, más que nunca, de activar la exportación» (Memoria L.U.R.E. 1898, p. 23).

114 «Desde que nuestra producción de aguarrás es dos veces mayor que el consumo nacional, y en las colofonias superiores, si no en tan grande proporción, excede mucho también la primera al segundo, es evidente que no se sostendrá la industria resinera española en su desarrollo, sin una exportación remuneradora» (Memoria L. U.R.E. 1899, p. 11). 
tieron algunas partidas hacia Francia e Italia «a precios más ventajosos aún que los de Amberes» 15 . Para estas fechas L.U.R.E. apreciaba ya «el excepcional crédito de que goza ya nuestra marca en el extranjero, solicitada y preferida por los más importantes consumidores que pagan por ellas precios más elevados que por las de otras procedencias». En el ejercicio de 1899 se accedió al mercado italiano y suizo, vendiéndose $287.378 \mathrm{~kg}$ y $119.008 \mathrm{~kg}$ de aguarrás, respectivamente, «a precios remuneradores por haber obtenido fletes reducidos que nos permiten competir con Francia y América, reducción conseguida por la importancia y normalidad de nuestros envíos» ${ }^{116}$. En cuanto a la colofonia, se estaban exportando a importantes casas inglesas e italianas las gamas de mayor calidad, donde el consumo peninsular excedía a la producción ${ }^{117}$.

Tal como parecen indicar las cifras representadas en los gráficos 3 y 4 , el mercado interior, una vez superada la crisis de 1898, se comportó con escaso dinamismo, siendo en las ventas realizadas en el exterior donde realmente se apoyó la expansión de L.U.R.E. Parece evidente, no obstante, que la distribución de ventas de L.U.R.E. no podría ser trasladada al conjunto del sector, donde las numerosas empresas medianas y pequeñas producian para el consumo interno. En todo caso, el desarrollo de la industria en su conjunto permitió evitar casi por completo la introducción de productos extranjeros «a cuyo fin no hemos vacilado en sacrificar nuestro precios» ${ }^{118}$.

\section{GRÁFICO 3}

Ventas de colofonia L.U.R.E., 1898-1923
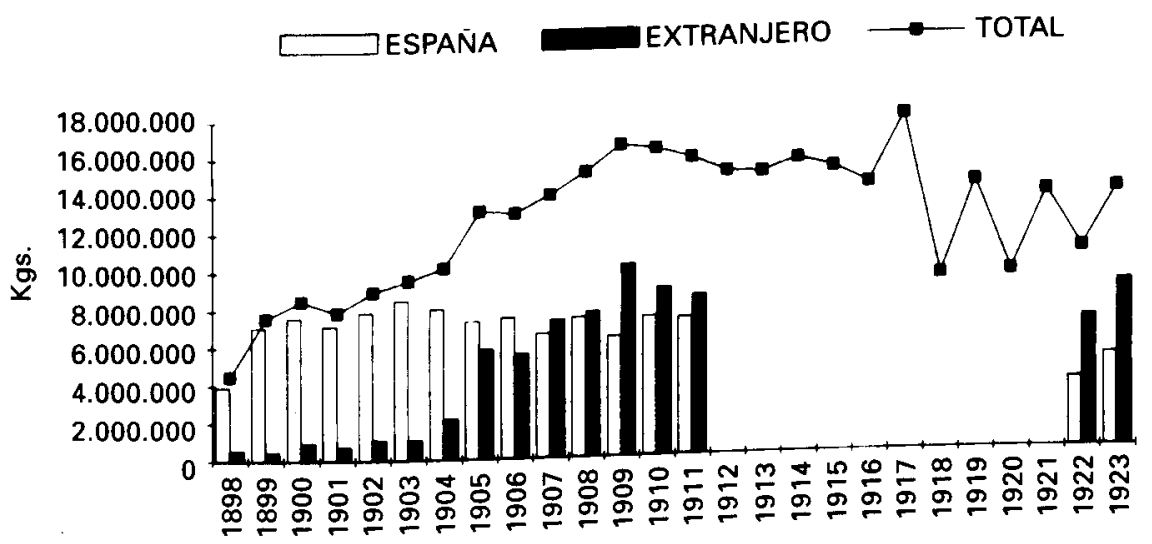

Fuente: Apéndice 4.

115 Memoria L.U.R.E. 1898 , p. 23.

116 Memoria L.U.R.E. 1899, p. 12.

117 Memoria L.U.R.E. 1899 , p. 12.

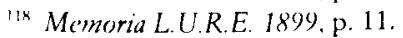




\section{GRÁFICO 4}

Ventas de esencia de trementina L.U.R.E., 1898-1923

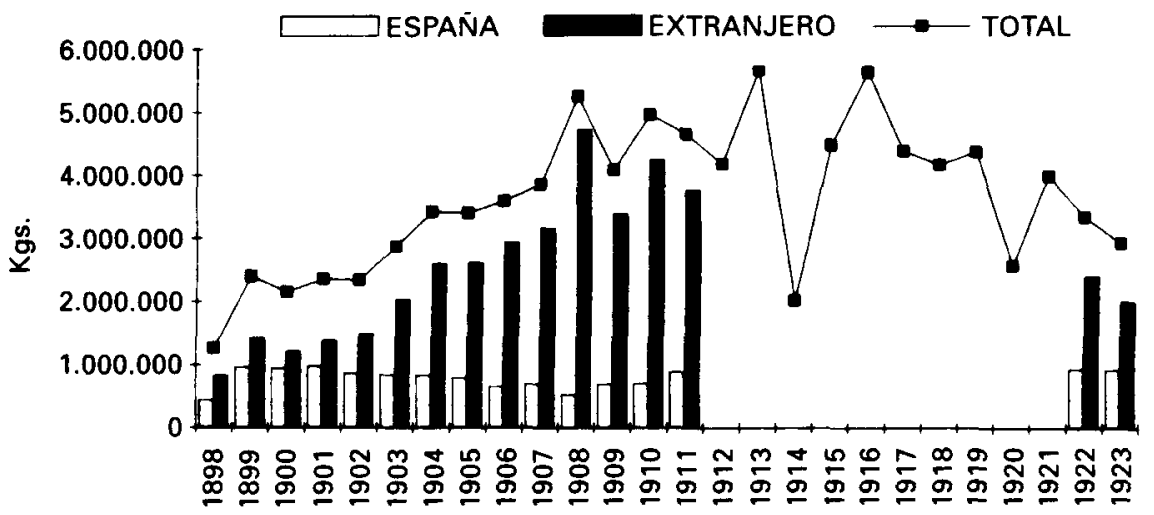

FUENTE: Apéndice 4.

Coyunturalmente, la expansión de la industria resinera española se detuvo hacia 1908. Las ventas disminuyeron y se produjo un descenso de los precios, tanto en el mercado internacional como en el interior, incidiendo de este modo sobre el conjunto del sector. A finales de 1909, tras una gradual vuelta a la normalidad, se inició una breve coyuntura de alza en los precios que se prolongaría hasta el mes de mayo de 1911, momento en el que una nueva caída de las cotizaciones sembró el desconcierto y la incertidumbre entre los industriales. Todo lo cual, al margen de los problemas puntuales de sobreproducción, no hacía sino reflejar los efectos de complejas operaciones bursátiles realizadas por operadores americanos y británicos que jugaban al alza o a la baja, tratando siempre de acumular ganancias especulativas en un mercado fácilmente manipulable desde la hegemonía americana ${ }^{119}$.

En vísperas de la I Guerra Mundial, la quiebra de la compañía norteamericana American Naval Stores, de Savannah, una de las empresas más importantes de la industria resinera mundial, y el desarrollo de la guerra de los Balcanes (19121913), fueron los dos hechos que determinaron la coyuntura. La guerra en los Balcanes dificultó el acceso a importantes mercados centroeuropeos y dio lugar a

119 «Al daño causado por el alza escesiva había que añadir el de la baja exagerada, que se presentaba, según el director de la Revista antes citada [Pins et Resineux], para el único y exclusivo objeto de favorecer los intereses de los especuladores americanos que juegan al alza o a la baja» (Anónimo, 1915, p. 9). 


\section{GRÁFICO 5}

Indice $(1907-1910=100)$ de cotizaciones medias de la esencia de trementina en diferentes mercados, 1907-1919

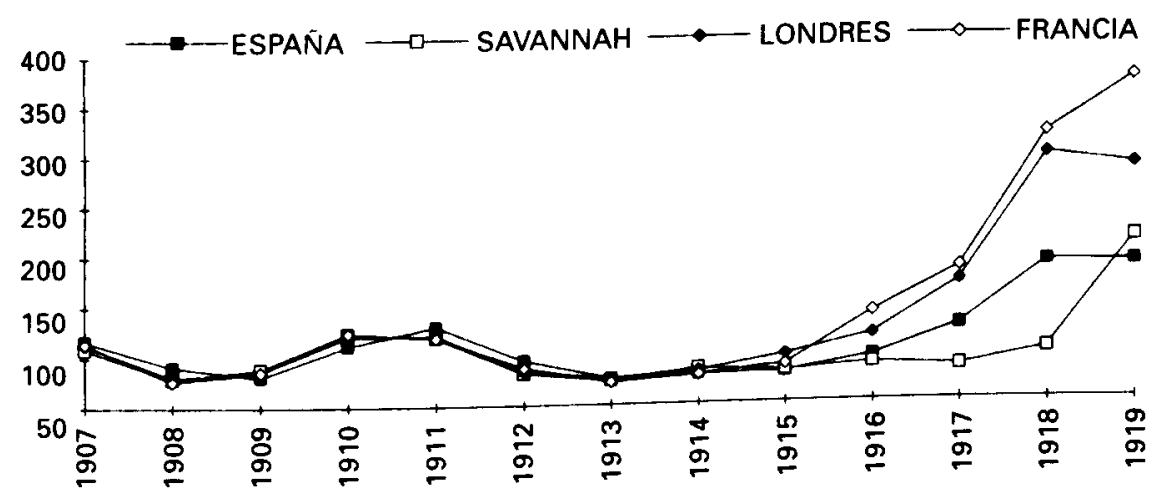

FUENTE: Apéndice 6.

\section{GRÁFICO 6}

Cotizaciones medias de distintas calidades de colofonia en el mercado de Savannab, 1906-07/1918-19

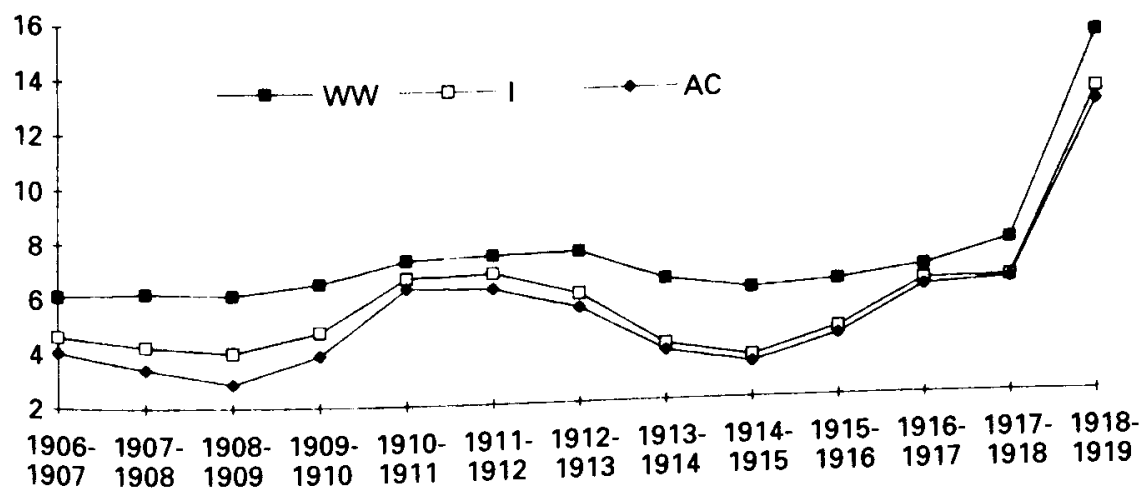

FuENTE: Apéndice 7. 
un retraimiento de las finanzas internacionales ${ }^{120}$. Por su parte, la quiebra de American Naval Stores obligó a la empresa a liquidar sus stocks a muy bajo precio, deprimiendo aún más los precios internacionales con un exceso añadido en la oferta ${ }^{121}$. Por otro lado, American Naval Stores había sido hasta entonces «el intermediario obligado para la colocación de la mayor parte del producto exportado desde América», de manera que, una vez desaparecida la citada sociedad, la incertidumbre y el desconcierto «hacen posible que productores y consumidores, a pesar de sus intereses antagónicos, viviendo al día, por miedo al mañana, contribuyan aunados al demérito del producto» ${ }^{122}$.

Aunque no podamos entrar en su estudio, el estallido de la Primera Guerra Mundial, cuando apenas los precios empezaban a recuperarse, supuso un cambio radical e inesperado en los mercados. Inicialmente, al igual que ocurrió en otros sectores, se extendió «el pánico y la desorientación en el comercio de resinosos» ${ }^{123}$. Durante los dos primeros años de la guerra, la escasez y carestía de los fletes, y la permanente incertidumbre de los precios retrajeron las ventas. Sin embargo, tras el desconcierto inicial, y aunque el volumen de ventas realizado en el exterior no pudo crecer debido a las circunstancias de la guerra, el espectacular incremento de los precios permitió la realización de extraordinarios beneficios industriales. Esta situación permitió que en España surgieran nuevos industriales que acabarían erosionando la indiscutible hegemonía alcanzada por L.U.R.E., entrando en una nueva y apasionante etapa de reestructuración de la industria resinera española.

\section{CONCLUSIONES}

El estudio de la industria forestal en su conjunto y de la resinera en particular requiere mayor esfuerzo del que hasta ahora le ha sido dedicado. El trabajo desarrollado en estas páginas apenas ha podido esbozar un esquema básico sobre el proceso evolutivo de una industria ubicada en un mundo rural, como el castellano, siempre calificado de inmovilista y conservador. Una visión cargada de pesimismo

120 «Paralizando la industria y creando un estado de perturbación en las naciones como España, ligadas por intereses a los beligerantes, que ha deprimido los mercados de dinero y dado lugar al retraimiento y carestia del mismo, impidiendo el desarrollo normal de la producción y del comercio» (Anónimo, 1915, p. 10).

121 «La perturbación llevada a los mercados resinosos con aquella liquidación ha sido enorme, ya que dio lugar, no sólo a una baja anormal en increible por sus proporciones en los precios de nuestros productos, y especialmente en los de las colofonias, sino que creó en algunos momentos graves dificultades en orden a la venta de éstas» (Memoria L.U.R.E. 1913-1914, p. 5 ).

122 Anónimo (1915), p. 10.

123 Anónimo (1930), p. 32. 
que no ha sido capaz siquiera de identificar la presencia de un sector que se encuentra en el reducido grupo de actividades transformadoras con presencia en los mercados internacionales y que llegó a ser una de las ramas de la química española más relevantes. La resinera es una industria que, por otro lado, también se ha visto afectada por la escasa atención que, incluso a nivel internacional, ha recibido el conjunto del sector químico. Situación que, recientemente, R. Landau y N. Rosenberg trataban de explicar argumentando la escasa visibilidad de una industria donde la mayor parte de la producción consiste en productos intermedios que ni siquiera llegan a ser conocidos por el consumidor y cuya diversidad y complejidad dificultan incluso el mero establecimiento de fronteras que permitan su definición, sin incurrir en clasificaciones arbitrarias o solapamientos con otros sectores productivos $^{124}$.

Ciertamente, en su larga historia, la industria resinera española se ha sostenido excesivamente centrada en la producción de unos productos semitransformados de elevada calidad y reconocido prestigio en los mercados internacionales, fracasando, en cambio, en el desarrollo de industrias derivadas o asociadas, tecnológicamente más exigentes y que hubieran permitido diversificar el sector y ampliar el consumo interno. De hecho, frente a la exportación de colofonia y esencia de trementina, España adquiría en el exterior una amplia gama de productos químicos en los que ambos productos eran sus componentes básicos (barnices, tintas, pinturas, alcanfor sintético, celuloide, etc.). No obstante, tal como apuntaban trabajos centrados en el estudio de los montes españoles en la segunda mitad del siglo XIX y primera del $\mathrm{XX}^{125}$, la explotación forestal se confirma como un subsector dinámico, donde se operaron transformaciones sustanciales en fechas relativamente tempranas y la industria resinera sería un buen ejemplo de intensificación y modernización de aprovechamientos y recursos tradicionales, bajo el impulso de una nueva economía de mercado.

De un modo u otro, alli donde avanzó la industrialización del bosque, se impusieron cambios que alteraron de manera irreversible determinadas estructuras sociales basadas en sistemas de acceso a los recursos forestales heredados del Antiguo Régimen. Es muy posible, incluso, que la individualización o privatización del monte acentuara la disparidad de rentas y las desigualdades en el seno de determinadas comunidades rurales, acelerando la proletarización del campesinado. Costes sociales y ecológicos que será necesario analizar con detenimiento. Sin embargo, el retroceso de los aprovechamientos vecinales, dio paso a nuevas formas de explotación que debieron atenuar el impacto negativo que sobre las economías

124 R. Landau y N. Rosenberg (1992), p. 74.

125 J. Sanz Fernández (1985 y 1986), J. I. Jiménez Blanco (1990), S. Zapata Blanco (1986), entre otros. 
campesinas tenía la pérdida de antiguos derechos sobre montes públicos. El incremento del empleo rural y los recursos obtenidos por los municipios en las subastas, también deberán ser estimados con mayor precisión si no queremos incurrir en generalizaciones demasiado apresuradas.

\section{APÉNDICE 1}

Número de pinos resinados en los montes de utilidad püblica

\begin{tabular}{|c|c|c|c|}
\hline & Distritos & Ordenaciones & Total \\
\hline 1900-1901 & 1.186 .935 & 1.594 .433 & 2.781 .368 \\
\hline 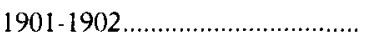 & 1.150 .867 & 1.759 .955 & 2.910 .822 \\
\hline $1902-1903 \ldots \ldots \ldots \ldots \ldots \ldots$ & $1,086.578$ & 1.869 .482 & 2.956 .060 \\
\hline 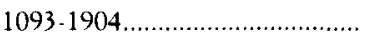 & 1.075 .449 & 1.918 .415 & 2.993 .864 \\
\hline 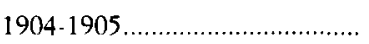 & 1.196 .585 & 1.991 .984 & 3.188 .569 \\
\hline $1905-1906 \ldots$ & 1.400 .340 & 1.974 .106 & 3.374 .446 \\
\hline 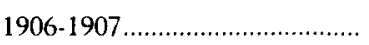 & 1.371 .621 & 2.003 .191 & 3.374 .812 \\
\hline $1907-1908 \ldots \ldots \ldots \ldots$ & 1.274 .384 & 3.399 .787 & 4.674 .171 \\
\hline $1908 \cdot 1909 \ldots \ldots$ & 1.117 .219 & 2.824 .827 & 3.942 .046 \\
\hline 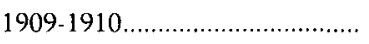 & 1.546 .101 & 2.752 .713 & 4.298 .814 \\
\hline \multicolumn{4}{|l|}{ 1910-1911 } \\
\hline 1911-1912 & 1.625 .874 & 2.655 .811 & 4.281 .685 \\
\hline $1912-1913 \ldots \ldots \ldots \ldots$ & 1.703 .202 & 3.065 .583 & 4.768 .785 \\
\hline $1913-1914 \ldots \ldots \ldots \ldots \ldots \ldots \ldots \ldots$ & 1.822 .691 & 2.898 .908 & 4.721 .599 \\
\hline $1914.1915 \ldots \ldots$ & 1.667 .572 & 3.284 .879 & 4.952 .451 \\
\hline 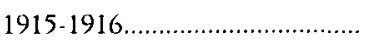 & 1.973 .853 & 3.507 .968 & 5.481 .821 \\
\hline 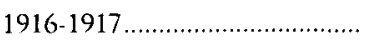 & 2.114 .581 & 3.698 .575 & 5.813 .156 \\
\hline 1917-1918 & 2.299 .903 & 3.670 .430 & 5.970 .333 \\
\hline 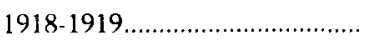 & 2.419 .172 & 3.250 .304 & 5.669 .476 \\
\hline $1919-1920 \ldots \ldots$ & 2.674 .139 & 4.003 .440 & 6.677 .579 \\
\hline 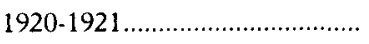 & 2.425 .069 & 3.936 .587 & 6.361 .656 \\
\hline $1921-1922 \ldots \ldots \ldots \ldots \ldots \ldots \ldots$ & & & 6.391 .314 \\
\hline 1922-1923 ......................... & & & 7.659 .442 \\
\hline $1923.1924 \ldots \ldots \ldots \ldots \ldots \ldots \ldots . .$. & & & 7.220 .526 \\
\hline $1924-1925 \ldots \ldots \ldots \ldots \ldots \ldots \ldots \ldots \ldots \ldots$ & & & 7.903 .081 \\
\hline $1925 \cdot 1926 \ldots \ldots \ldots \ldots \ldots \ldots \ldots \ldots \ldots \ldots$ & & & 8.776 .182 \\
\hline $1926-1927$ & & & 9.656 .325 \\
\hline $1927-1928 \ldots \ldots \ldots \ldots \ldots \ldots$ & & & 9.799 .845 \\
\hline $1928 \cdot 1929 \ldots \ldots \ldots \ldots \ldots \ldots \ldots$ & & & 10.051 .083 \\
\hline \multicolumn{4}{|l|}{ 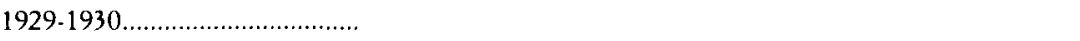 } \\
\hline 1930-1931 & & & 10.119 .816 \\
\hline \multicolumn{4}{|l|}{$1931-1932 \ldots \ldots \ldots \ldots$} \\
\hline 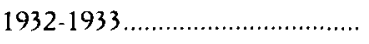 & & & 11.064 .322 \\
\hline
\end{tabular}

FUENTE: Estadistica(s) general(es) de la producción de los montes de utilidad pública. 


\section{APÉNDICE 2}

La Unión Resinera Española. Número de pinos en resinación, 1898-1933

\begin{tabular}{|c|c|c|c|c|}
\hline & \multirow[b]{2}{*}{ Propios } & \multicolumn{2}{|c|}{ Arrendados } & \multirow[b]{2}{*}{ Total } \\
\hline & & Particulares & Públicos & \\
\hline 1898 & & & & 3.000 .000 \\
\hline 1899 & & & & 3.600 .000 \\
\hline 1900 & & & & 4.800 .000 \\
\hline 1901 & & & & 4.140 .000 \\
\hline $1902 \ldots \ldots \ldots \ldots \ldots \ldots \ldots$ & & & & 4.892 .000 \\
\hline $1903 \ldots \ldots \ldots \ldots \ldots \ldots \ldots$ & & & & 5.785 .693 \\
\hline 1904 & & & & 6.278 .485 \\
\hline 1905 & & & & 6.758 .537 \\
\hline 1906 & & & & 7.103 .400 \\
\hline 1907 & & & & \\
\hline 1908 & & & & 9.014 .700 \\
\hline 1909 & & & & 9.874 .300 \\
\hline 1910 & & & & 9.337 .500 \\
\hline 1911 & & & & 9.541 .600 \\
\hline 1912 & & & & 9.400 .100 \\
\hline 1913 & & & & 9.637 .700 \\
\hline 1914 & & & & 9.575 .300 \\
\hline 1915 & & & & 9.406 .000 \\
\hline $1916 \ldots$ & & & & 9.437 .900 \\
\hline 1917 & & & & 9.643 .700 \\
\hline $1918 \ldots \ldots \ldots \ldots \ldots \ldots \ldots$ & & & & 9.408 .100 \\
\hline 1919 & & & & 9.265 .200 \\
\hline $1920 \ldots \ldots \ldots \ldots \ldots \ldots \ldots \ldots$ & & & & 8.254 .100 \\
\hline $1921 \ldots$ & & & & 7.810 .800 \\
\hline $1922 \ldots \ldots$ & & & & 7.822 .900 \\
\hline $1923 \ldots \ldots \ldots \ldots \ldots \ldots$ & & & & 7.672 .900 \\
\hline $1924 \ldots \ldots \ldots \ldots \ldots \ldots$ & & & & 6.893 .000 \\
\hline 1925 & & & & 7.900 .000 \\
\hline $1926 \ldots$ & 2.377 .531 & & & 8.587 .579 \\
\hline 1927 & & & & 9.091 .388 \\
\hline $1928 \ldots \ldots \ldots \ldots \ldots \ldots$ & 2.410 .772 & 1.680 .909 & 4.105 .548 & 8.197 .229 \\
\hline 1929 & 2.416 .728 & 1.591 .486 & 4.238 .310 & 8.246 .524 \\
\hline $1930 \ldots \ldots$ & 2.412 .482 & 1.537 .271 & 4.265 .895 & 8.215 .648 \\
\hline $1931 \ldots \ldots \ldots \ldots \ldots \ldots$ & 2.377 .816 & 1.498 .445 & 4.250 .997 & 8.127 .258 \\
\hline 1932 & 2.407 .408 & 1.329 .856 & 2.979 .436 & 6.716 .700 \\
\hline 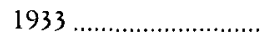 & 2.423 .885 & 1.353 .776 & 3.084 .346 & 6.862 .007 \\
\hline
\end{tabular}

FUt:NTL: Memorias L.U.R.E., 1898-1933. 


\section{APÉNDICE 3}

La Unión Resinera Española. Producción, $1898-1933$ (Kgs)

\begin{tabular}{|c|c|c|c|c|}
\hline & Miera & $\begin{array}{l}\text { Esencia de } \\
\text { trementina }\end{array}$ & Colofonia & Varios \\
\hline 1898 & & 1.866 .000 & 6.534 .000 & \\
\hline 1899 & & 2.336 .000 & 8.375 .000 & \\
\hline 1900 & & 2.379 .000 & 8.167 .000 & \\
\hline 1901 & & 2.287 .000 & 7.972 .000 & \\
\hline 1902 & & 2.549 .000 & 8.706 .000 & \\
\hline 1903 & & 3.146 .000 & 10.825 .000 & \\
\hline 1904 & & 3.440 .000 & 12.090 .000 & \\
\hline $1905 \ldots \ldots$ & & 3.589 .000 & 12.157 .000 & \\
\hline 1906 & & 4.204 .342 & 14.115 .222 & \\
\hline 1907 & & 4.610 .756 & 15.350 .547 & \\
\hline 1908 & & 4.684 .712 & 15.766 .465 & \\
\hline 1909 & & 4.652 .594 & 15.369 .629 & \\
\hline 1910 & & 4.727 .873 & 15.235 .741 & \\
\hline $1911 \ldots \ldots \ldots \ldots$ & & 4.477 .355 & 16.214 .797 & \\
\hline 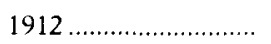 & & 4.971 .161 & 16.820 .258 & \\
\hline 1913 & & 4.892 .395 & 16.842 .460 & \\
\hline 1914 & & 4.977 .652 & 16.077 .709 & \\
\hline 1915 & & 4.331 .429 & 16.239 .545 & \\
\hline $1916 \ldots \ldots \ldots \ldots \ldots$ & & 4.868 .871 & 14.364 .773 & 48.419 \\
\hline 1917 & & 4.599 .066 & 13.918 .298 & 60.829 \\
\hline 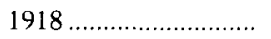 & & 4.101 .384 & 11.397 .619 & 48.262 \\
\hline 1919 & & 3.647 .656 & 11.397 .619 & 96.129 \\
\hline $1920 \ldots$ & & 3.498 .162 & 11.050 .924 & 58.985 \\
\hline 1921 & & 3.189 .686 & 11.147 .117 & 85.986 \\
\hline $1922 \ldots \ldots \ldots \ldots \ldots \ldots \ldots \ldots \ldots$ & & 3.073 .921 & 10.802 .610 & 45.950 \\
\hline 1923 & & 3.154 .847 & 10.836 .818 & 66.265 \\
\hline 1924 & & 3.002 .609 & 10.455 .429 & 47.277 \\
\hline $1925 \ldots \ldots$ & 15.856 .556 & 3.357 .306 & 11.428 .516 & 57.212 \\
\hline $1926 \ldots$ & 18.466 .077 & 3.799 .302 & 13.491 .237 & 47.471 \\
\hline 1927 & 20.123 .909 & 4.147 .580 & 14.629 .162 & 42.749 \\
\hline $1928 \ldots \ldots \ldots \ldots \ldots \ldots$ & 18.940 .817 & 3.930 .992 & 13.996 .315 & 72.938 \\
\hline 1929 & 20.126 .841 & 4.171 .333 & 14.608 .898 & \\
\hline $1930 \ldots \ldots \ldots \ldots \ldots \ldots \ldots \ldots$ & 20.749 .891 & 4.289 .576 & 15.005 .207 & \\
\hline $1931 \ldots \ldots \ldots \ldots \ldots \ldots \ldots \ldots$ & 19.855 .067 & 4.092 .190 & 14.174 .026 & \\
\hline $1932 \ldots \ldots \ldots \ldots \ldots$ & 15.751 .347 & 3.192 .961 & 11.076 .277 & \\
\hline 1933 & 16.732 .618 & 3.366 .122 & 11.950 .771 & \\
\hline
\end{tabular}

Futivt: Memorias L.U.R.E., 1898-1933 


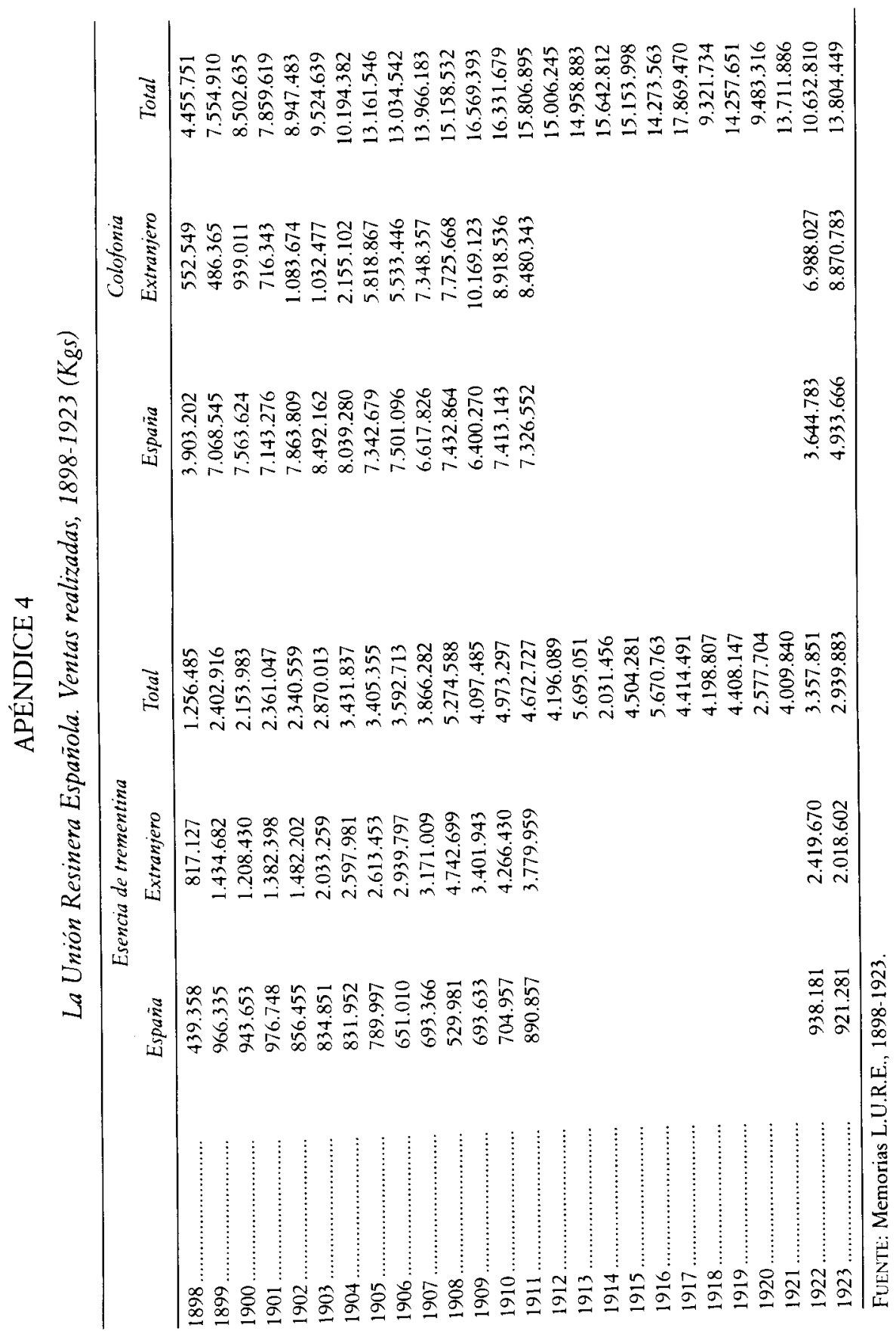




\section{APÉNDICE 5}

Producción de resina en los montes de utilidad pública (Kgs)(1)

\begin{tabular}{|c|c|c|c|}
\hline & Distritos & Ordenaciones & Total \\
\hline 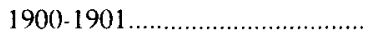 & 3.044 .103 & 5.025 .619 & 8.069 .722 \\
\hline $1901-1902 \ldots \ldots \ldots \ldots$ & 2.775 .735 & 5.693 .743 & 8.469 .478 \\
\hline $1902.1903 \ldots \ldots \ldots$ & 1.544 .689 & 6.107 .520 & 7.652 .209 \\
\hline 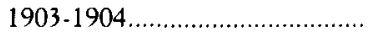 & 2.554 .957 & 6.878 .336 & 9.433 .293 \\
\hline $1904-1905 \ldots \ldots \ldots$ & 2.799 .254 & 6.891 .015 & 9.690 .269 \\
\hline $1905-1906 \ldots \ldots \ldots \ldots \ldots \ldots \ldots$ & 3.262 .889 & 6.611 .052 & 9.873 .941 \\
\hline 1906-1907 & 3.230 .274 & 6.511 .443 & 9.741 .717 \\
\hline $1907-1908 \ldots \ldots \ldots$ & 3.010 .893 & 11.058 .236 & 14.069 .129 \\
\hline 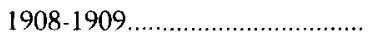 & 2.789 .516 & 7.085 .298 & 9.874 .814 \\
\hline 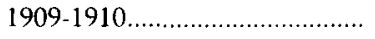 & 3.440 .257 & 8.086 .024 & 11.526 .281 \\
\hline \multicolumn{4}{|l|}{ 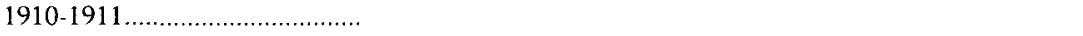 } \\
\hline 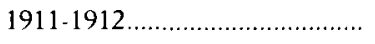 & 3.952 .971 & 8.265 .249 & 12.218 .220 \\
\hline $1912-1913 \ldots \ldots \ldots \ldots$ & 3.919 .177 & 7.634 .838 & 11.554 .015 \\
\hline $1913-1914 \ldots \ldots \ldots \ldots$ & 4.257 .837 & 7.509 .781 & 11.767 .618 \\
\hline 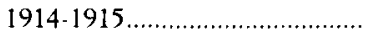 & 4.028 .686 & 8.605 .497 & 12.634 .183 \\
\hline $1915-1916 \ldots \ldots \ldots \ldots \ldots \ldots$ & 4.844 .912 & 10.210 .433 & 15.055 .345 \\
\hline 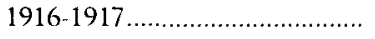 & 5.145 .646 & 11.650 .380 & 16.796 .026 \\
\hline $1917-1918 \ldots \ldots \ldots$ & 5.713 .986 & 7.715 .501 & 13.429 .487 \\
\hline $1918-1919 \ldots \ldots \ldots \ldots \ldots \ldots \ldots \ldots \ldots$ & 5.475 .142 & 7.629 .205 & 13.104 .347 \\
\hline $1919.1920 \ldots \ldots \ldots \ldots$ & 4.985 .439 & 9.896 .903 & 14.822 .342 \\
\hline 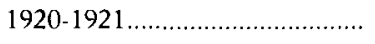 & 5.581 .670 & 9.805 .808 & 15.387 .478 \\
\hline $1921-1922 \ldots \ldots \ldots \ldots \ldots \ldots \ldots \ldots \ldots$ & & & 16.352 .818 \\
\hline $1922-1923 \ldots \ldots \ldots \ldots \ldots \ldots \ldots \ldots \ldots \ldots$ & & & 19.955 .473 \\
\hline $1923-1924 \ldots \ldots \ldots \ldots \ldots \ldots \ldots \ldots \ldots \ldots \ldots \ldots \ldots \ldots$ & & & 18.726 .267 \\
\hline $1924-1925 \ldots \ldots \ldots \ldots \ldots \ldots \ldots \ldots \ldots \ldots \ldots \ldots$ & & & 19.737 .733 \\
\hline $1925-1926 \ldots \ldots \ldots \ldots \ldots \ldots \ldots \ldots \ldots \ldots \ldots$ & & & 21.279 .487 \\
\hline 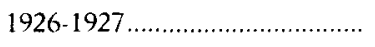 & & & 23.757 .803 \\
\hline $1927-1928 \ldots \ldots \ldots \ldots \ldots \ldots \ldots \ldots \ldots \ldots$ & & & 26.667 .054 \\
\hline 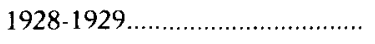 & & & 24.583 .404 \\
\hline 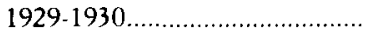 & & & 26.246 .000 \\
\hline 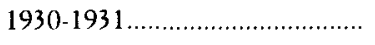 & & & 26.500 .336 \\
\hline $1931-1932 \ldots \ldots \ldots \ldots \ldots \ldots \ldots \ldots \ldots$ & & & 26.888 .862 \\
\hline 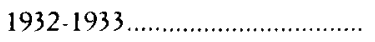 & & & 26.458 .538 \\
\hline
\end{tabular}

(1) Para los años 1900-1901/1909-1910 la producción ha sido estimada a través de los rendimientos provinciales del período 1910-1911/1915-1916, diferenciando ordenaciones y distritos.

FUENTE: Estadistica(s) general(es) de la producción de los montes de utilidad pública. 


\section{APÉNDICE 6}

Cotizaciones medias de la esencia de trementina en diferentes mercados

\begin{tabular}{|c|c|c|c|c|}
\hline & España(1) & Savannab(2) & Londres(3) & Francia(4) \\
\hline 1907 & 114,09 & 57,64 & 44,54 & 96 \\
\hline 1908 & 89 & 41,98 & 31,61 & 64,65 \\
\hline $1909 \ldots \ldots \ldots \ldots \ldots \ldots$ & 78,75 & 46,8 & 33,95 & 71,4 \\
\hline $1910 \ldots \ldots \ldots$ & 108,38 & 65,65 & 47,54 & 103,5 \\
\hline $1911 \ldots \ldots \ldots \ldots \ldots \ldots$ & 126,74 & 62,97 & 47,57 & 99,5 \\
\hline $1912 \ldots \ldots \ldots \ldots \ldots \ldots$ & 92,54 & 43,23 & 33,06 & 73 \\
\hline $1913 \ldots \ldots \ldots \ldots \ldots \ldots \ldots$ & 74,16 & 39,28 & 30,03 & 60,85 \\
\hline 1914 & 77,05 & 44,96 & 32,45 & 66 \\
\hline 1915 & 77,86 & 43,12 & 38,17 & 73 \\
\hline 1916 & 92,21 & 46,16 & 45,9 & 116 \\
\hline 1917 & 121,68 & 44,42 & 66,55 & 153 \\
\hline $1918 \ldots \ldots \ldots \ldots \ldots \ldots \ldots$ & 182,88 & 53,1 & 116,52 & 266 \\
\hline 1919 & 181,88 & 112,1 & 112,27 & 313 \\
\hline $1920 \ldots \ldots \ldots \ldots \ldots \ldots$ & 288,88 & 157,09 & 165,38 & 619 \\
\hline 1921 & 183,27 & 60,62 & 71,47 & 265 \\
\hline 1922 & 220,32 & 108,31 & 97,36 & 430 \\
\hline
\end{tabular}

(1) En pesetas por unidad de $100 \mathrm{Kgs}$. con envase.

(2) En centavos por galón con envase.

(3) En chelines por quintal inglés con envase.

(4) En francos por unidad de $100 \mathrm{Kgs}$. sin envase (media de los mercados de Dax y Burdeos)

FUENTE: Savannah Weekly Naval Stores Review; Memorias L.U.R.E., R. Sargos, 1949. 


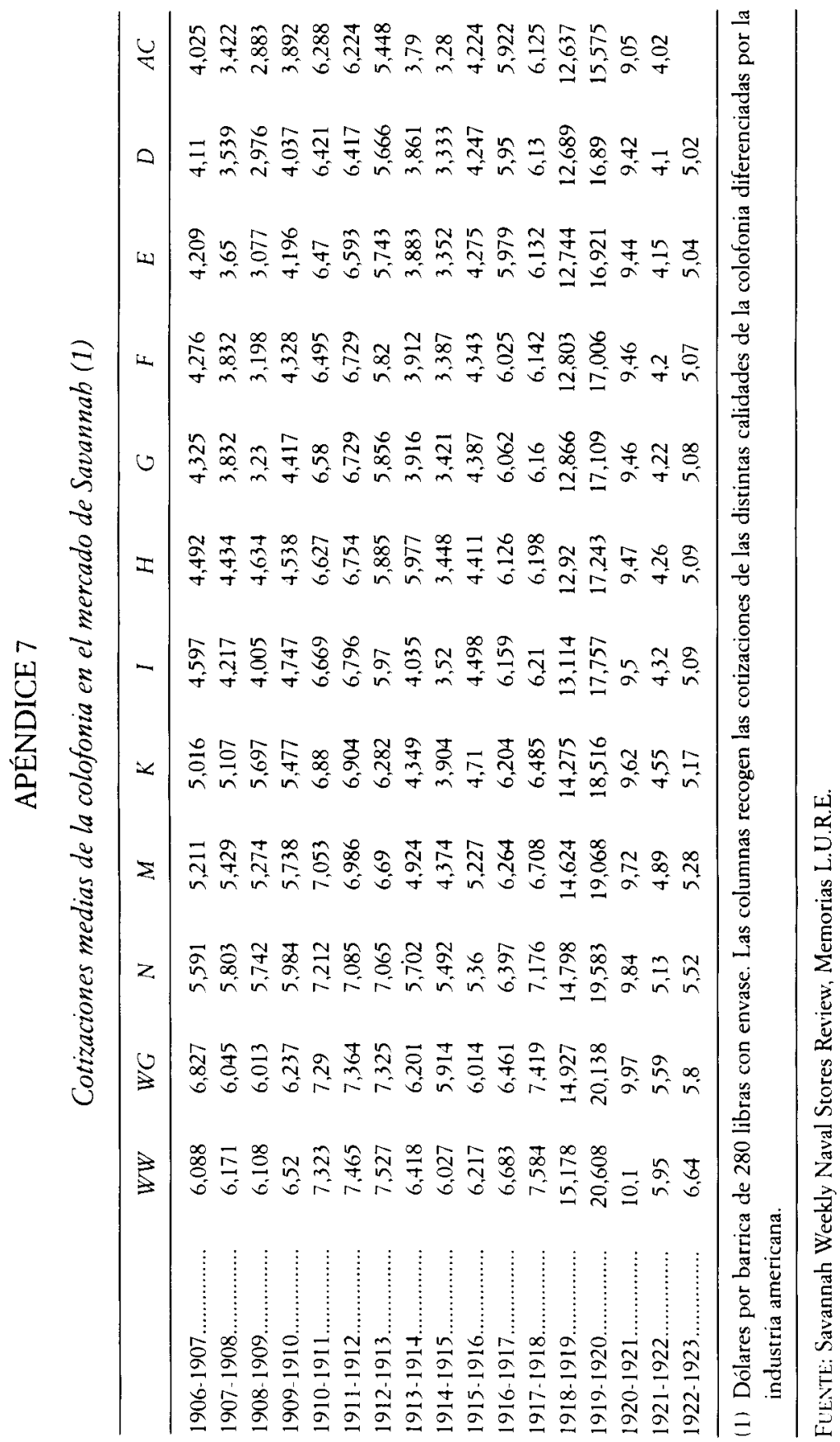

